NBER WORKING PAPER SERIES

\title{
SOCIAL SECURITY REFORMS AND THE CHANGING RETIREMENT BEHAVIOR IN GERMANY
}

Axel H. Börsch-Supan

Johannes Rausch

Nicolas Goll

Working Paper 27518

http://www.nber.org/papers/w27518

\author{
NATIONAL BUREAU OF ECONOMIC RESEARCH \\ 1050 Massachusetts Avenue \\ Cambridge, MA 02138 \\ July 2020
}

This paper is part of the National Bureau of Economic Research's International Social Security (ISS) Project. The ISS Project is supported by the National Institute on Aging (grants P01 AG012810 and P30-AG012810) and by the U.S. Social Security Administration through grant \#5-RRC08098400-10 to the National Bureau of Economic Research as part of the SSA Retirement Research Consortium. The findings and conclusions expressed are solely those of the authors and do not represent the views of SSA, any agency of the Federal Government, or the National Bureau of Economic Research. The authors thank Marius Cziriak, Elisabeth Gruber and Hannah Horton for their excellent research assistance.

NBER working papers are circulated for discussion and comment purposes. They have not been peerreviewed or been subject to the review by the NBER Board of Directors that accompanies official NBER publications.

(C) 2020 by Axel H. Börsch-Supan, Johannes Rausch, and Nicolas Goll. All rights reserved. Short sections of text, not to exceed two paragraphs, may be quoted without explicit permission provided that full credit, including $\odot$ notice, is given to the source. 
Social Security Reforms and the Changing Retirement Behavior in Germany

Axel H. Börsch-Supan, Johannes Rausch, and Nicolas Goll

NBER Working Paper No. 27518

July 2020

JEL No. H55,J26

\begin{abstract}
$\underline{\text { ABSTRACT }}$
As much like other industrialized countries, in recent decades the employment rate in Germany for those aged 55 to 69 had been declining first to considerably rise again afterwards. This paper investigates the role of structural policy changes, in particular reforms of the pension system, since 1980 in explaining this trend reversal. We summarize the institutional changes and pension reforms that may account for the trend reversal, and calculate an "implicit tax on working longer". We find that for both men and women the increase in the employment rate coincides with a reduction in the early retirement incentive. The reduction of incentives mainly stems from the introduction of actuarial deductions for early retirement and from the abolishment of specific early retirement pathways.

Axel H. Börsch-Supan

Munich Center for the Economics of Aging Max Planck Institute

for Social Law and Social Policy

Amalienstrasse 33

80799 Munich

GERMANY

and NBER

boersch-supan@mea.mpisoc.mpg.de

Johannes Rausch

Munich Center for the Economics of Aging

Max Planck Institute

for Social Law and Social Policy

Amalienstraße 33

80799 Munich

Germany

rausch@mea.mpisoc.mpg.de

Nicolas Goll

Munich Center for the Economics of Aging

Max Planck Institute

for Social Law and Social Policy

Amalienstraße 33

80799 Munich

Germany

Goll@mea.mpisoc.mpg.de
\end{abstract}




\section{Introduction}

As in the other countries in this volume, the retirement age in Germany has declined for a long time. This has put enormous fiscal pressures on Germany’s pension system. Since about 2000, however, working in later life has been making a stunning comeback. Among the 12 countries involved in the study, Germany has experienced the largest increase in the employment rate of the 55-69 age group, see Figure 1 . This figure and the remainder of the paper refer to West Germany in order to avoid confounding pension policy effects with the strong unification effects in East Germany after 1989. West Germany used to feature a relatively low level of old-age employment with a rate of only 36.8/21.5 percent (men/women) in 2000 for the 55-69 age group. 16 years later, this rate has reached a stunning 59.5/48.6 percent (OECD, 2018a). The trend reversal is particularly pronounced among men, see Figure 1, while the picture is a bit more complex for women who experienced a rather constant increase for the 55-59 age group and a mild reversal for the other age groups. The trends in labor force participation (LFP) are very similar (not shown).

\section{Figure 1: West German employment rate by age group and gender}

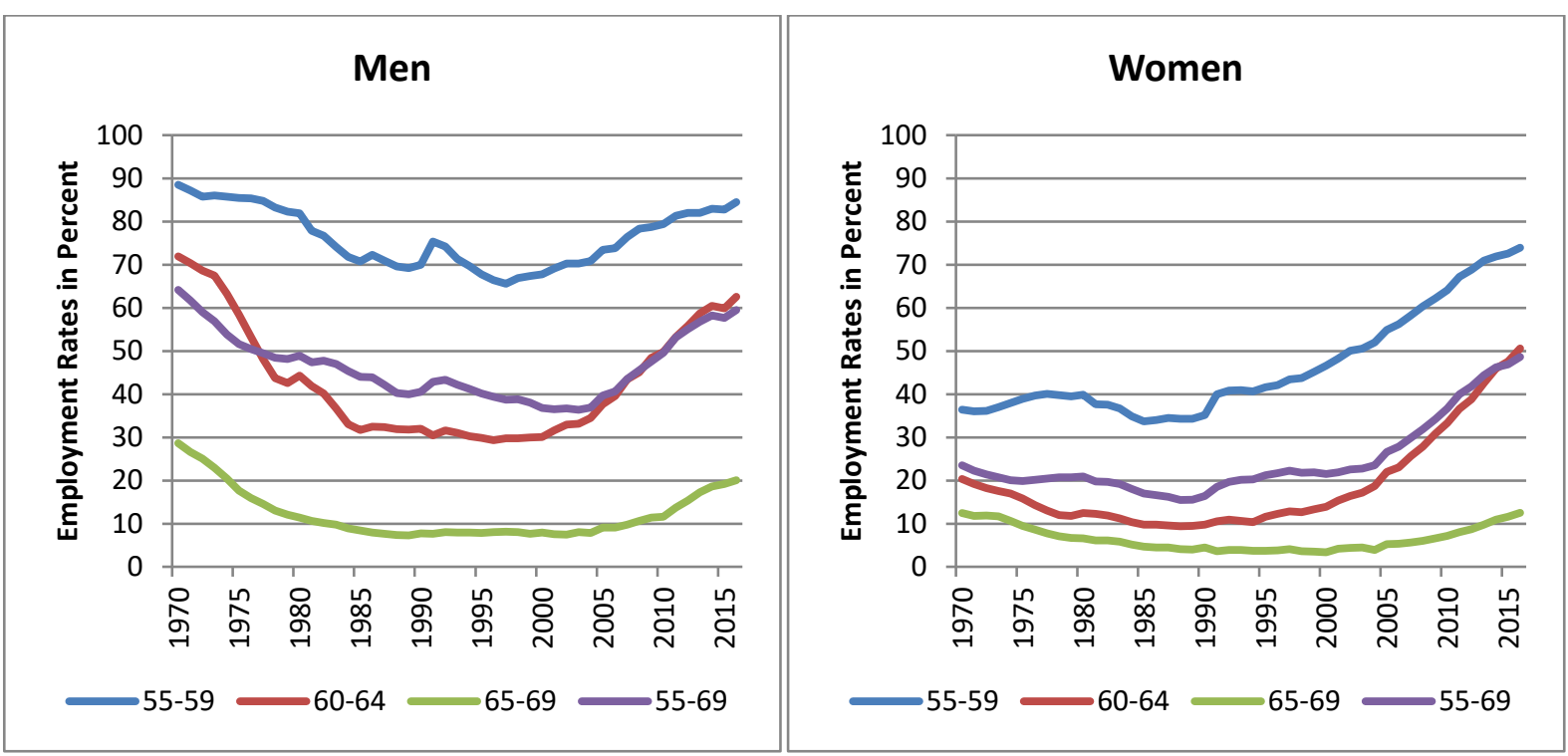

Source: Authors' own calculations based on OECD and German Federal Statistical Office.

Understanding the causes for this recent increase in employment and LFP is important if one wants to assess whether the current rising trend will continue, thus reducing the negative consequences of ageing on fiscal sustainability. If the reversal is mainly caused by transitory or one-off events old-age labor force participation may slow down again in the near future. However, if it is caused by a structural change, we may expect a lasting impact on fiscal sustainability.

One set of causes for the trend reversal in employment could be historical trends. Younger cohorts are healthier and have been better educated, permitting longer working lives. Moreover, the role of women in society has dramatically changed, affecting LFP of both genders. The previous phase of the ISSP has shown that these secular developments have contributed astonishingly little to the trend reversal (Börsch-Supan 
and Coile 2018 for an overview; Börsch-Supan and Ferrari 2017 for Germany). In fact, even if many of the historical trends studied earlier may have contributed to the overall level of labor force participation, their trend does not show the U-shape pattern observed for labor force participation.

This paper therefore investigates the role of structural policy changes since 1980. Our evidence presented suggests that much of the trend reversal of older men's labor force participation may be explained by changes in Germany's public pension rules, in particular by the phasing in of actuarial adjustments for early retirement. Regarding women's LFP, it is less clear how much public pension rules play a role. Most probably, the secular change of women's role in society is the main driver of the steadily increasing LFP among the younger West German women while we observe more of a trend reversal among older women.

The paper is organized as follows. Section 2 describes the changes in the German labor force participation and pension claiming behavior between 1980 and 2016. Section 3 provides a summary of the institutional changes and pension reforms in Germany that might be the causes for the stunning trend reversal. Section 4 is the main methodological part of the paper and describes how we boil down the institutional changes into a few key statistics, especially the "implicit tax on working longer”. Section 5 presents our results. We show how the implicit tax on working longer has changed between 1980 and 2016, using several alternative specifications and robustness checks. We then graphically relate the implicit tax on working longer to the prevailing employment rate. Section 6 concludes. We find a negative correlation between the employment rate and the incentives to claim benefits early. In other words, as the implicit tax on working longer decreased, employment at older ages increased.

This evidence is highly suggestive. However, such a bivariate correlation does not control for the many other potential explanatory factors and the heterogeneity in the population. This requires a much more elaborate multivariate analysis. The next step of the ISSP will be devoted to a causal analysis of the role of public pension policies in shaping LFP. This paper is contributing to this effort by constructing time series of the implicit tax for a small set of stylized household types. The next step will be to apply this machinery to real households in a population-representative survey, and to embed our incentive variables, the macro variables considered in Börsch-Supan and Coile (2018) and other determinants into an econometric analysis of retirement and labor force participation.

\section{Employment rate among older individuals and pension claiming behavior}

In this section we will take a closer look at the development of the employment rate of older workers and their actual pension claiming behavior. It is important to note that labor market exit and the begin of pension benefit claiming may not take place at the same time. We therefore avoid the term "retirement" as much as we can since in many languages it ambiguously refers to both decisions which may be driven by different considerations and determinants. We also take care to distinguish between the group of older workers and 
the group of insured individuals. They do not precisely overlap. For instance, homemakers and emigrated workers do not belong to the German labor force but often have earned pension claims in Germany. We, therefore, first look at changes in employment and then at changes in claiming behavior.

\section{Employment rate}

West Germany shares with other industrialized countries a "U-shape" pattern in the employment rate (labor force participation rate) of older workers over time. In its downward-phase from 1970 into the $1990 \mathrm{~s}^{1}$ the employment rate of older men (age group 55-69) declined by 23.7 percentage points to 40.5 percent until 1990 (see Figure 1). Even more pronounced was this decline for the age group 60 to 64 with a decrease by 40 percentage points to 31.8 percent until 1990. The decline was much smaller for women with 7.1 (10.6) percentage points for the age group 55 to 69 (60 to 64). However, their employment rate was with 23.5 percent already rather small in 1970. Most studies (e.g. Börsch-Supan 1992, Siddiqui 1997, Börsch-Supan and Schnabel 1999, Hanel 2010) identified the introduction of early retirement opportunities as main reason for the decline. The downward-phase ended in the 1990s. A stagnation phase followed with more or less constant employment rates before the employment rates started to increase around the year 2000. The older men's employment rate then began to rise at a rather fast pace. Until now the employment rate of older men has increased by 22.7 (32.5) percentage points for the age group 55 to 69 (60 to 64). The women's employment rates started to increase earlier and stronger. However, in the women's case the increase of labor force participation among younger women has to be taken into account. If we correct the development of the older women's employment rates for this general trend we receive a similar pattern as for men. ${ }^{2}$ So adjusted, the employment rate for women increased between 2000 and 2016 by approximately 18.7 (31.4) percentage points for the age group 55 to 69 (60 to 64) (see Figure 2).

\footnotetext{
${ }^{1}$ The employment rate of whole Germany includes another drop in 1991. However, this drop results mainly from the unification of Germany and the small employment rates in East Germany. For younger age groups we also observe an increase in the employment rate after 1990 due to the unification.

${ }^{2}$ We correct for the general trend by subtracting from the growth rate of the employment rate of the 60 to 64 year old workers the growth rate of the employment rate of the 50 to 54 year old worker. We consider thereby the growth rates of the same cohorts. The correction is consequently kept quite simple.
} 
Figure 2: West Germany older women's employment rate with and without correction for general trend in younger women's employment rates.

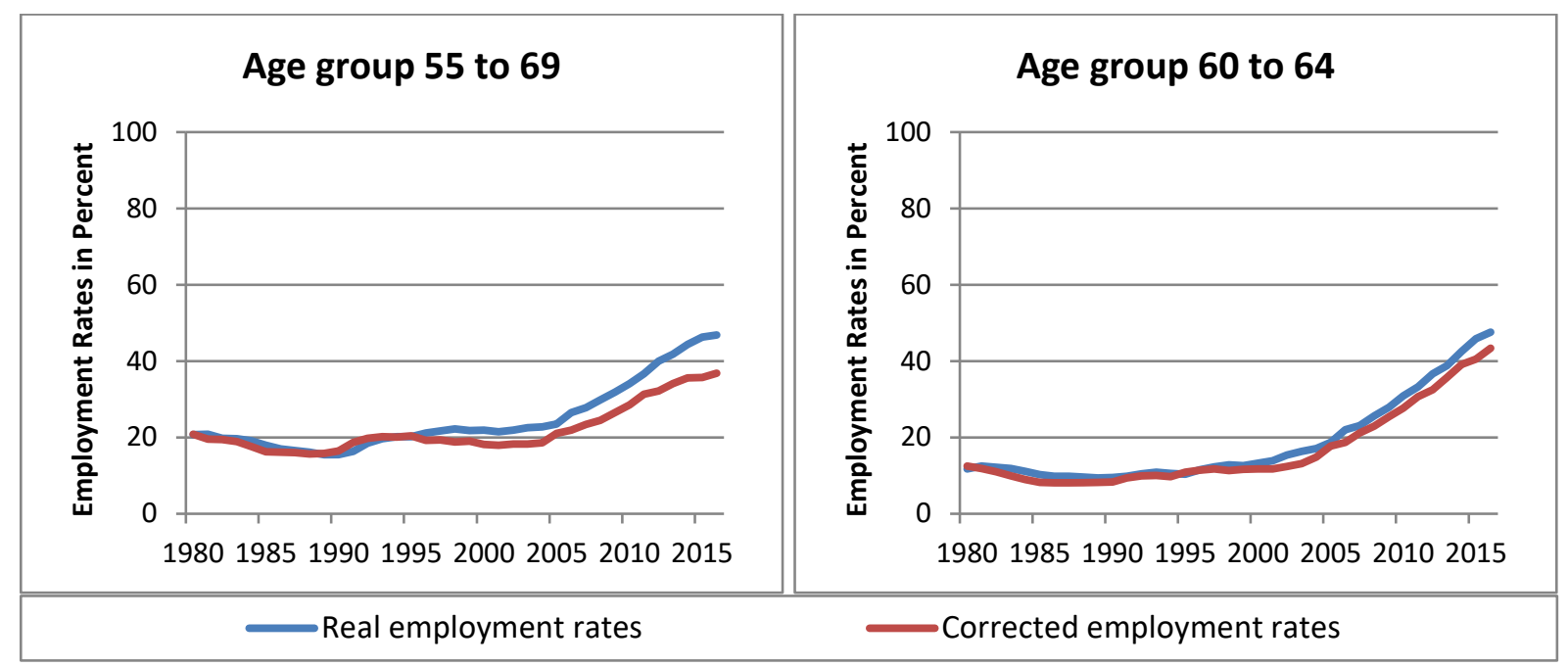

Source: Authors' own calculations based on OECD (2018a), Statisitsches Bundesamt (2016).

\section{Pension claiming behavior}

As already mentioned, the labor force is not identical to the insured population. Consequently, the development of the employment rate may vary from the actual pension claiming behavior. Figure 3 depicts the average pension claiming age of West German men and women separately for old-age pensions, disability pensions and overall pensions. In the men's case, we observe that the general average claiming age increased between 1980 and 2015 steadily from 58.2 to 61.9. On the other hand, the average claiming age for old-age pension remained similar to the employment rate constant until 2000. The average pension claiming age stayed, thereby, slightly below 63. Afterward it increased by 1.6 years to the age 64 . While the pension claiming ages increases over all pensions, the claiming age of disability pensions dropped in 1984 by 1.3 years and decreased after 1992 with an accelerating pace by another 2.7 years. At first glance the drop in the claiming ages of disability pension seems strange since the requirements for disability pensions were tightened in 1984 and 2001 (see next chapter). However, due to the tighter requirements the misuse of the disability pension as early retirement pathway for healthy individuals had been blocked. Hence, the average claiming age decreased since fewer older but healthy workers misused the disability pension and the share of younger but disabled workers increased in all variants of the German disability pension. The overall pension claiming age increased since the share of individuals who claimed a regular old-age pension among all new pension claims increased (see Figure 4). 
Figure 3: Average pension claiming age by gender (West Germany).

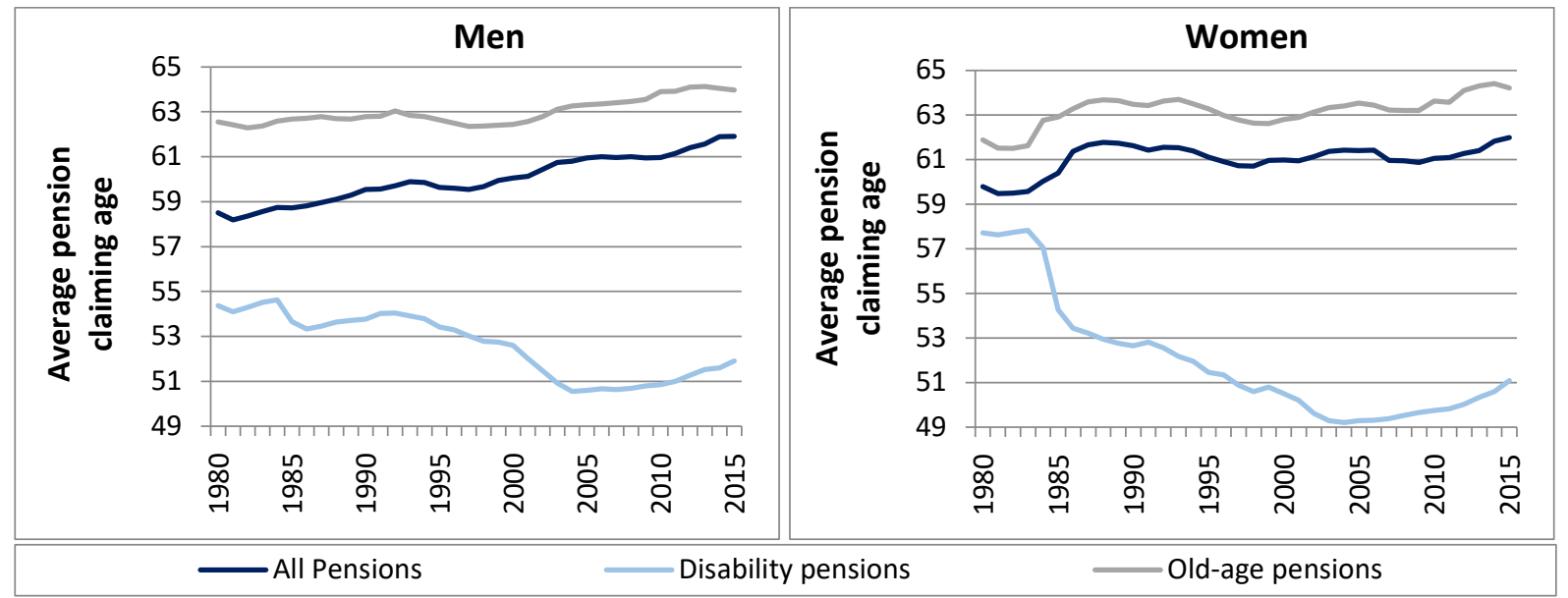

Source: Deutsche Rentenversicherung Bund, Rentenzugang (see DRV, 2017).

Figure 4: Coverage of pathways to retirement on annual newly claimed pensions.

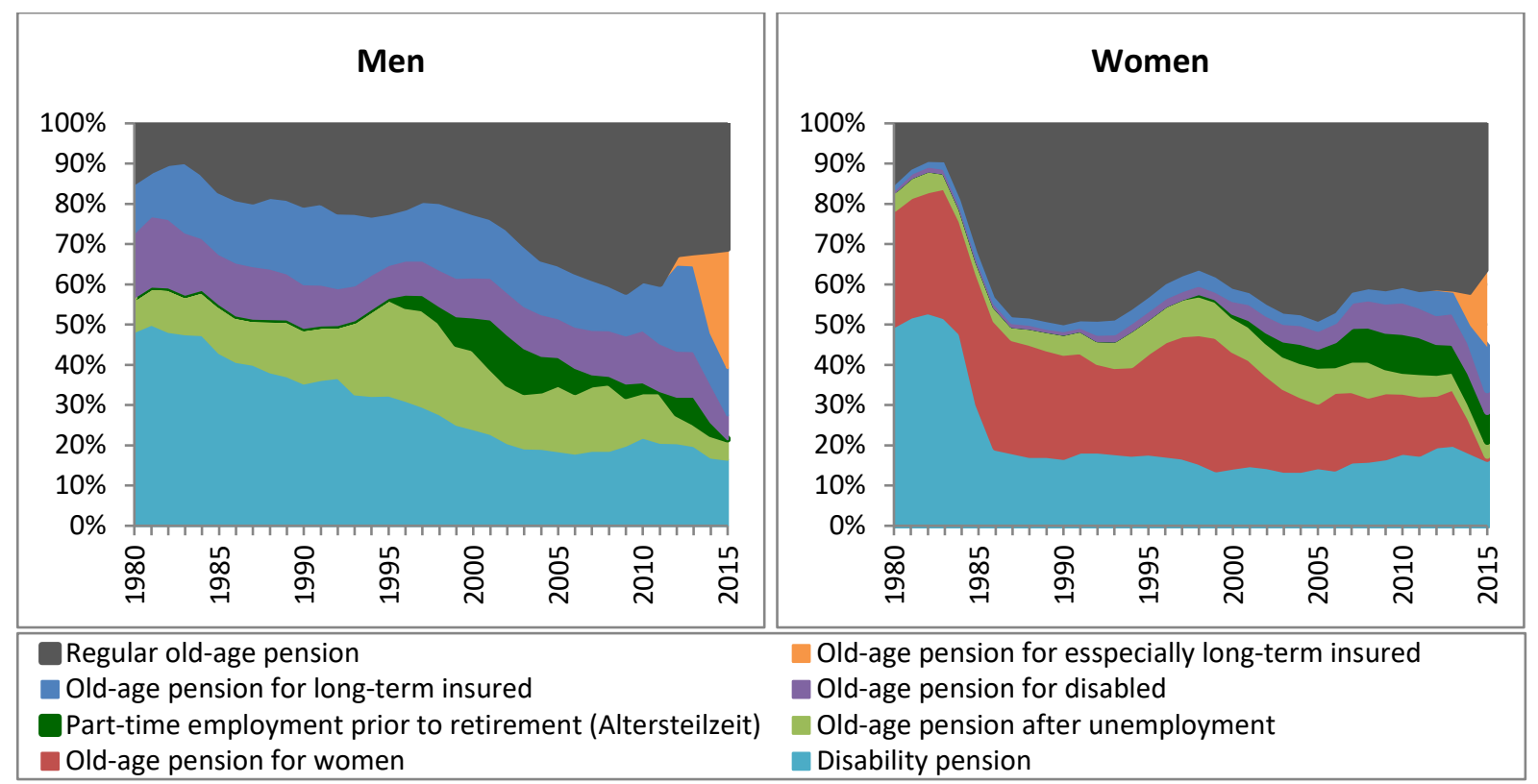

Source: Deutsche Rentenversicherung Bund, Rentenzugang (see DRV, 2017).

For women, the development of the average pension claiming age for old-age pensions is nearly identical with the development of the average pension claiming age over all pensions. We observe merely a one year gap between both variables. At least after 1984 the average pension claiming age of disability pensions seems to play a secondary role due to its small fraction on all pension claims (see Figure 4). The pension claiming age over all pensions (as well as all old-age pensions) rose after 1984 by 2.1 years while the claiming age of disability pensions dropped by 4.5 years. As we will see in the following section, this pattern can be explained with the 1984 pension reform which changed the requirements for a disability pensions and for a regular old-age pensions. It seems that many women older than 61 did not fulfil the old vesting period for a regular old-age pension of 15 years while they did fulfil the shorter 5 years waiting time of a disability pension. Since at the same time the requirements for disability pension were tightened older women switched from claiming disability pensions to claim (regular) old-age pensions. As a 
consequence the average claiming age for disability pension dropped while the claiming age for regular old-age pension rose. After 1990 the claiming ages of old-age pensions remained first at an almost constant level before it decreased by one year until 2000. However, similar to the development of the employment rate also the women's claiming age increased again since 2000. On the other hand, the women's average pension claiming age of disability pensions decreased by another 4 years until 2004 before it rose again by 2 years.

All in all, the development of the men's average claiming age of old-age pensions is consistent with the observed development of their employment rate. Only the decline in the employment rate between 1980 and 1985 cannot be observed in the considered time period. For women the comparison between the pension claiming behavior and the employment rate is less straightforward, especially until 2000. One reason may be the differences in the considered groups. While the employment rate includes only the share of women working (in Germany) the average pension claiming age takes the claiming ages of all insured women into account. The employment rate could, therefore, miss certain changes in the pension claiming patters of women.

In a last step, we study the distribution of the pension claiming age by ages and its development over time (see Figure 5). In the men's case we observe three major pension claiming ages. These are the ages 60, 63 and 65 which are at the same time the earliest claiming ages for the most important pension pathways (see next chapter and Table 1). Between 1980 and 2002 most individuals claimed a pension at age 60. However, the relevance of the age decreased rapidly with the introduction of actuarial deduction in 1999 and the abolishment of old-age pension because of unemployment in 2012. At the same time, pension claimings at the regular eligibility age of 65 increased. The share of pension claimed at the eligibility age of 63 remained at first nearly constant. However, in the last years it got more relevant for two reasons. First, the old-age pension with lower eligibility ages were abolished and second the actuarial deductions for claiming a pension at 63 were temporarily abolished for certain individuals (“pension with 63”). For the remaining ages, we can, moreover, observe a shifting process from early to later ages.

For women two major pension claiming ages can be observed. First, the eligibility age for the old-age pension for women at age 60 and second the statutory eligibility age at 65 . Similar to the men's case the share of pension claimings at age 60 declined after 1999 in two steps. The first drop after 1999 reduced the share on all pension claimings by almost 20 percentage points while the second drop, which occurred 2012 (abolishment of the old-age pension for women), covered a decline of 15 percentage points. At the same time the earliest eligibility age for long-term insured (age 63) became more relevant. In total, the share of women claiming a pension at age 63 increased from 2.4 percent to 28.2 percent. Nonetheless, with over 40 percent most women claimed their pension at the statutory eligibility age. Similar to the men's case between the age 60 and 63 a shifting process can be observed which moves the pension claiming form smaller to higher ages. 
Figure 5: Pension claiming by age and year (1985-2015) in West Germany.

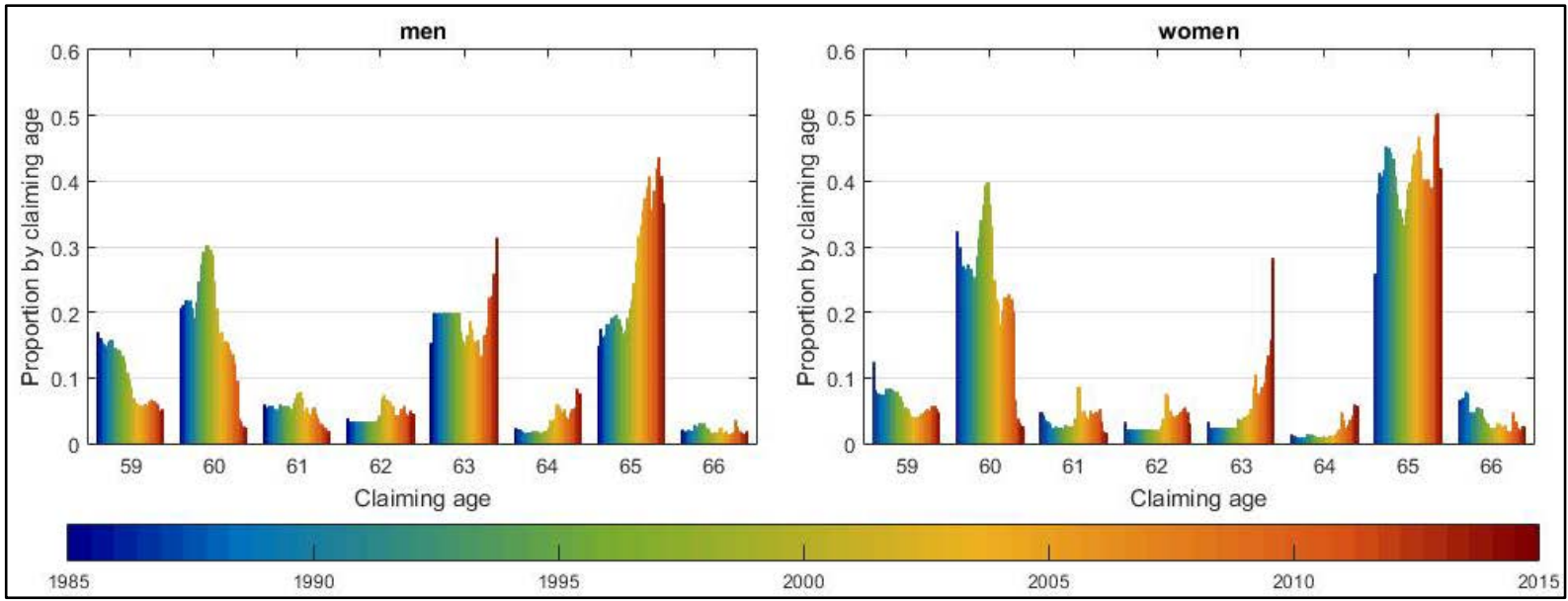

Source: Deutsche Rentenversicherung Bund, Rentenzugang (see DRV, 2017).

\section{Institutional changes: The German Pension Policy and its Development}

The main hypothesis of this paper is that the reversals in labor supply and pension claiming behavior around the year 2000 are to a large extent driven by changes in pension policies. To this end, this section presents the policy changes that occurred since 1980 and are salient for changes in retirement behavior. We start with a brief summary of the structure of the Germany pension system in 1980 in order to assess the initial situation of the system at the beginning of the time span considered in this study.

\subsection{The German Pension System until 1980}

The German pension system originally began as a funded disability insurance scheme in 1889, but was quickly broadened into a general old-age security system with both disability pensions and old-age pensions. The statutory eligibility age was set to 65. After two world wars and a period of hyperinflation about half of the capital stock was lost and the system was transformed into a pay-as-you-go (PAYG) system in 1957. Benefits from this public PAYG system were designed to maintain the living standard that was achieved during the working life also to the time of retirement. Therefore, individual pension benefits were set to be proportional to the individual labor income averaged over the entire working career such that the relative income position of an individual during the working life would be preserved during retirement. While the absolute level of pension benefits has been reduced in the subsequent reforms, the principle of maintain the relative income position has been maintained until today. The German public pension system therefore features only few redistributive properties, much less than, e.g., the US Social Security system. The main redistribution instrument to prevent old-age poverty is a kind of minimum pension at the social assistance level that was introduced in 2001. The system is mandatory for all workers except for most self- 
employed, civil servants and workers with earnings below the official minimum earnings threshold. In the case of the main earner's death spouses and children are, moreover, protected through survivor benefits.

After anchoring the public pension benefits to gross wages in 1958, several pathways to claim a public pension before the statutory eligibility age were introduced in the 1960s and 1970s which enabled especially women, unemployed and disabled persons to claim a pension at age 60 and individuals with long service lives (i.e. at least thirty-five insurance years) to claim a pension at age 63, see Table 1. These early retirement pathways permitted an earlier claim of pension benefits but were based on the already earned pension claims with exactly the same benefit calculations as a regular old-age pension (see Table 1, BörschSupan and Jürges 2012). Until 1992, there were no actuarial deductions for claiming a pension before the statutory eligibility age. However, actuarial supplements of 7.5 percent (15 percent) were granted for postponing the pension claiming by one (two) years.

Table 1: Pathways to retirement.

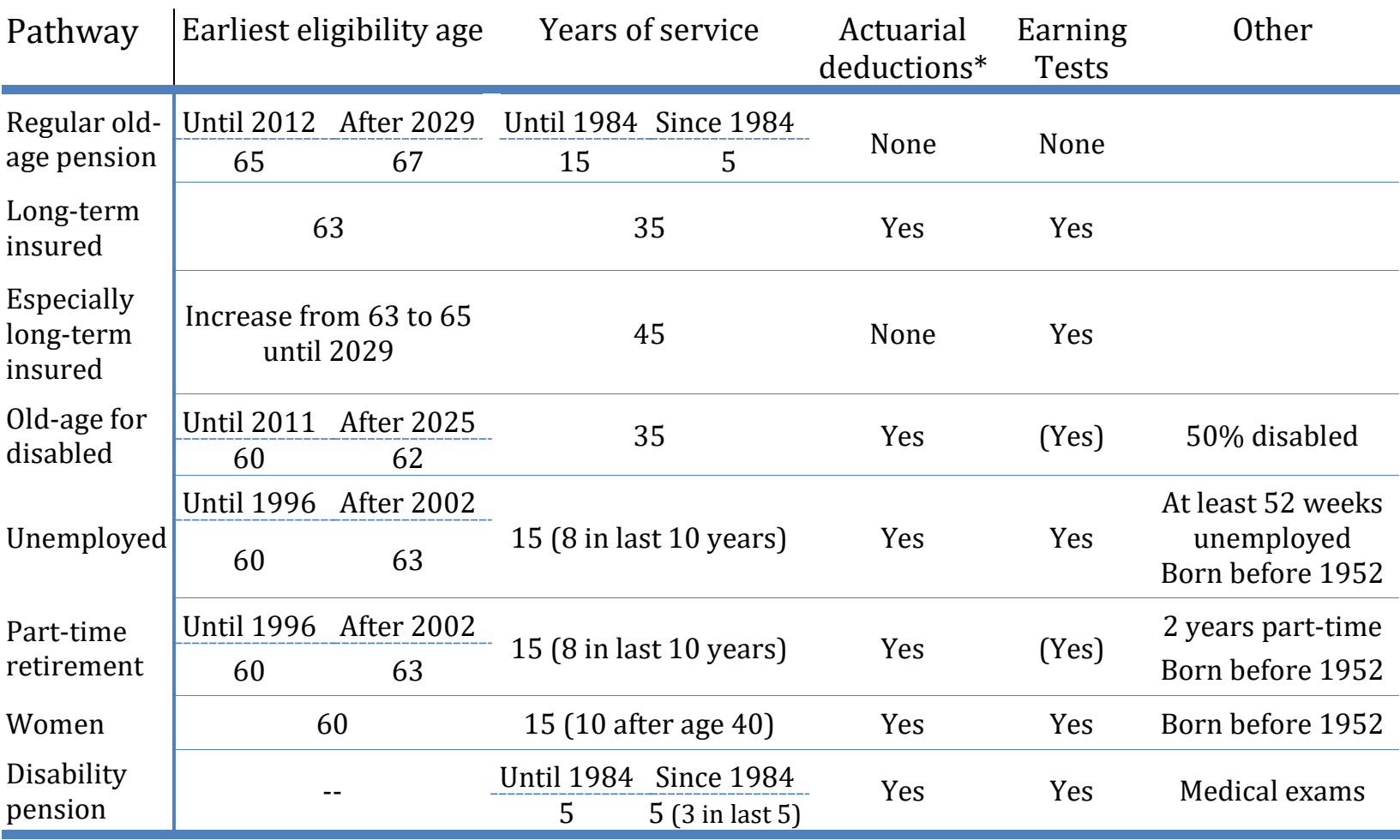

Note: * Introduction of actuarial deductions between 1992 and 2004.

Source: Authors' own table.

The reforms in the 1960s and 1970s led to one of the world's most generous pension system with various opportunities to claim a pension at the age of 60 (Table 1) and net replacement rates around 70 percent (Table 2). The "standard net replacement rate" in this table refers to a German convention which relates the net pension income to the net earnings of a synthetic pensioner who constantly earned the average wage during the entire service life of 45 years. Replacement rates relating to the last earnings are presented in Section 5. 
Table 2: Standard net replacement rate and standard net replacement rate before taxes ${ }^{3}$.

\begin{tabular}{|c|c|c|c|c|c|}
\hline Year & $\begin{array}{c}\text { Standard net } \\
\text { replacement } \\
\text { rate }\end{array}$ & $\begin{array}{l}\text { Standard net } \\
\text { replacement } \\
\text { rate before } \\
\text { taxes }\end{array}$ & Year & $\begin{array}{c}\text { Standard net } \\
\text { replacement } \\
\text { rate }\end{array}$ & $\begin{array}{c}\text { Standard net } \\
\text { replacement } \\
\text { rate before } \\
\text { taxes }\end{array}$ \\
\hline 1980 & 70.3 & 57.6 & 1998 & 70.9 & 53.6 \\
\hline 1981 & 69.9 & 57.4 & 1999 & 70.5 & 53.3 \\
\hline 1982 & 71.5 & 58.4 & 2000 & 69.7 & 52.9 \\
\hline 1983 & 71.3 & 57.9 & 2001 & 68.6 & 52.6 \\
\hline 1984 & 72.0 & 58.1 & 2002 & 69.0 & 52.9 \\
\hline 1985 & 71.8 & 57.4 & 2003 & 69.6 & 53.3 \\
\hline 1986 & 70.2 & 56.4 & 2004 & 67.9 & 53.0 \\
\hline 1987 & 70.6 & 56.2 & 2005 & & 52.6 \\
\hline 1988 & 70.3 & 56.3 & 2006 & & 52.2 \\
\hline 1989 & 70.7 & 56.1 & 2007 & & 51.3 \\
\hline 1990 & 67.6 & 55.0 & 2008 & & 50.5 \\
\hline 1991 & 67.4 & 53.9 & 2009 & & 52.0 \\
\hline 1992 & 67.1 & 53.1 & 2010 & & 51.6 \\
\hline 1993 & 67.0 & 53.4 & 2011 & & 50.1 \\
\hline 1994 & 69.5 & 54.8 & 2012 & & 49.4 \\
\hline 1995 & 70.1 & 53.9 & 2013 & & 48.9 \\
\hline 1996 & 70.2 & 53.4 & 2014 & & 48.1 \\
\hline 1997 & 71.5 & 54.0 & 2015 & & 47.7 \\
\hline
\end{tabular}

Note: The Standard net replacement rates base on the regular old-age pension of an individual with 45 earning points, the so called Eckrentner. It is the official stated replacement rate.

Source: Deutsche Rentenversicherung Bund, Kenngrößen und Bemessungswerte (see DRV, 2017).

\subsection{Reform process since 1980}

The generous German public pension system proved to be financially unsustainable. This precipitated a sequence of reform steps starting around 1980, see Figure 6.

Elements of reform included the introduction of actuarial adjustments to the claiming age, a gradual increase of the eligibility ages, the closure of many early retirement pathways, a significant reduction of benefit generosity, the abolishment of earnings tests and the introduction of partial ("flexible") retirement. The reform process can be divided in three phases. The first phase lasted until 1992 and can be described as a very cautious, limited and at times contradictory departure away from the previous era of increasing generosity. The second phase took place between 1992 and 2007 and consisted of several incisive reforms leading to a sustainable pension system. The third phase covers the time since 2007 and entailed some reform backlash such as the introduction of a new early retirement pathway.

\footnotetext{
${ }^{3}$ The standard net replacement rate before taxes considers the contributions to the social security system but no tax payments. It is used in Germany since 2005 instead of the standard net replacement rate as pension benefits are not anymore taxed consistently due to a stepwise introduction of a deferred taxation regulation (see reforms 2004).
} 
Figure 6: Timeline of the reforms to the social security system.

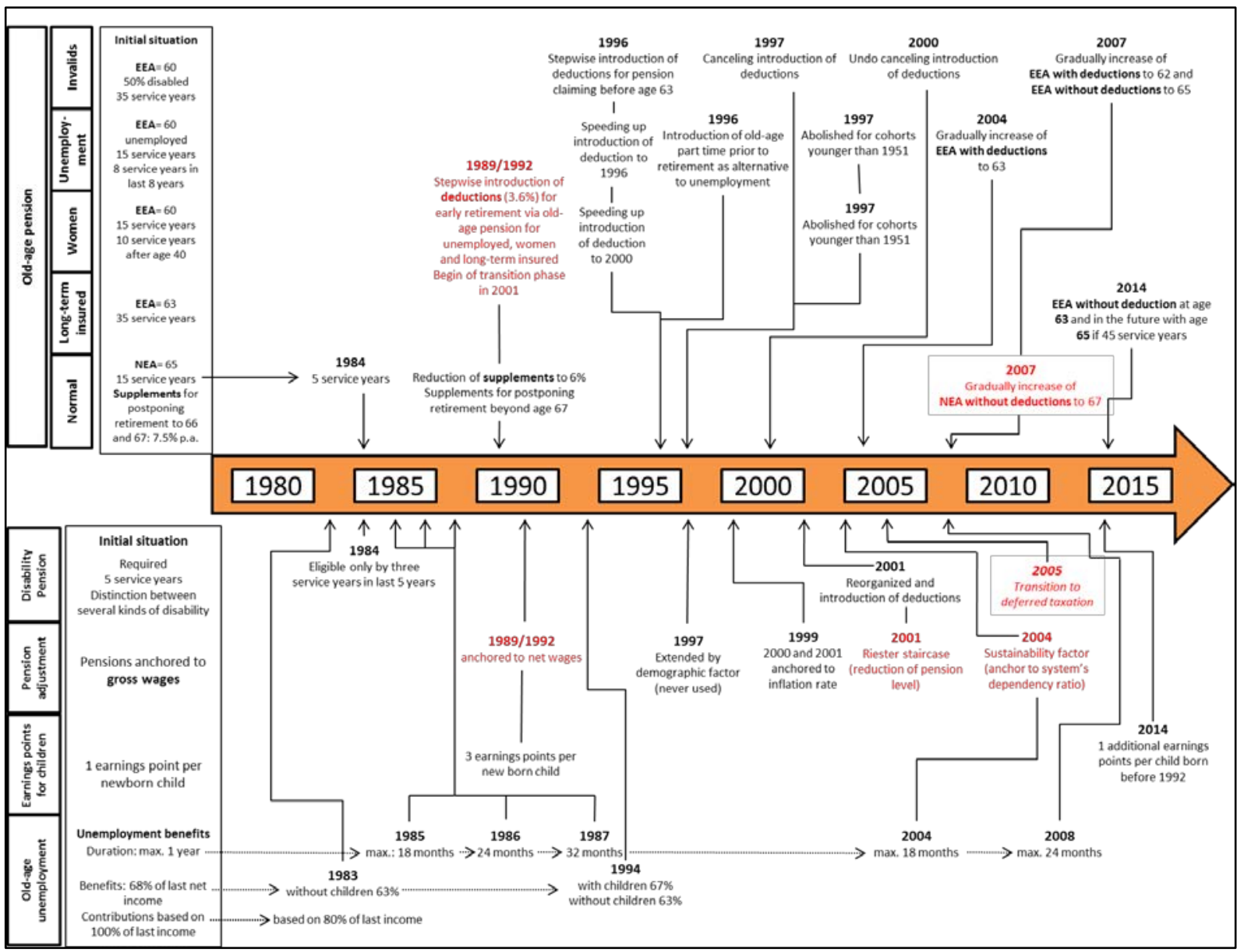

Source: Authors' own diagram.

Phase 1 (1980 to 1992): Modest retrenchment within the pension system/Increasing generosity outside the pension system

With the $\mathbf{1 9 8 4}$ reform the requirements for disability pensions were tightened by making a minimum of three contribution years in the last five years a condition. Moreover, stricter medical examinations were introduced. As kind of compensation the vesting period for regular old-age pensions was reduced from 15 to 5 service years, which resamples the former not medical condition for disability pensions. Together this gravely changed the balance between newly claimed old-age pension and disability pension in favor of oldage pensions. As Figure 4 depicts this was especially the case for the women's pension claiming behavior. The share of claimed disability pensions on all newly claimed pension dropped for women by over 30 percentage points while the share of regular old-age pension increased by the same amount. This strong effect has two reasons. First, the number of women fulfilling the new requirements for disability pensions dropped since many women stopped working after marriage or childbirth and had therefore paid no contributions in the last five year. Second, for similar reasons women maybe were only able to claim disability pensions as they did not fulfilled the former vesting period of 15 service years for a regular oldage pension. 
In a contradictory move, the opportunity to leave the labor market early was widened between $\mathbf{1 9 8 4}$ and 1987 by extending the maximal duration time of unemployment benefits for older workers (age 56 and above) from 12 months to 32 months. In fact since unemployment benefits are neither means tested nor do they require job-search attempts they are often used "to build a bridge to retirement". The extension of the duration time widened this "bridge”. Moreover, severance pay became tax advantage for employers what facilitated for the employee to find an agreement with the employer regarding ending the employment relationship with the right to claim unemployment benefits.

\section{Phase 2 (1992 to 2007): Sustainability Reforms}

\section{Step 2.1 (1992): Toward actuarial adjustments and more flexibility}

The 1992 pension reform which passed the parliament 1989 represents a significant landmark in the German pension policy as it marks the leap into an era of reforms striving to increase the system's sustainability. As first step of this process the 1992 pension reform introduced two significant changes to the pension system's framework. First, it switched the benefit adjustment from gross wage growth to net wage growth. This measure got rid of an odd situation where increasing social contribution rates would have led to a circle of rising net replacement rates. Second, starting in 2001 it provided a phased introduction (by cohorts) of actuarial adjustments for an early pension claiming. This measure started a long sequence of changes in the system of pathways to retirement and their eligibility ages with and without actuarial adjustments. They are graphically displayed in Figure 7 at the end of this section; each panel a) through h) presents an element in this sequence.

The stepwise introduction of actuarial adjustments dealt with the strong incentives to claim a pension early as they reduce pension benefits by 3.6 percent per year of early pension claiming (counted from the statutory eligibility age or a respective earlier adjustment-free eligibility age, see Table 6). However, these actuarial adjustments are not actuarial neutral as several studies showed (see Werding, 2012 and Gasche, 2012); hence an incentive to claim a pension early remains. Proper actuarial neutral adjustment would have to be at least twice as large as the current ones. Parallel to the introduction of actuarial deduction the actuarial supplements for postponing the pension claiming beyond the statutory eligibility age were changed. From 1992 onward actuarial supplements were granted for each year of later pension claiming (not only for the first two years). However, at the same time the actuarial supplements were reduced to 6 percent per year of later retirement (actuarial deduction of 20 percent).

Beside these sustainability-increasing measures, the 1992 pension reform contained two additional components. First, the number of earnings points parents receive for new born children were increased from one to three. Second, a partial old-age pension was introduced which enabled individuals to compensate an income loss due to a reduction in working hours (part-time work) by drawing a partial pension. The partial pension could be drawn, however, only for certain proportions of the split between work and retirement: one third, one half, or two thirds. The earning limits were calculated individually based on the 
labor income of the last three years before drawing the partial pension. In the end this pension scheme was not successful as only every few individuals used it.

In 1996 the timetable for the introduction of the actuarial adjustment was moved up to 1997 for the old-age pension because of unemployment and to 2000 for the old-age pension for women (see Figure 7c). Moreover, it was decided to phase in actuarial adjustments for the old-age pension for disabled persons (see Table 6).

Parallel the old-age pension because of unemployment was enlarged to the old-age pension because of unemployed and part-time work for employees over 55. ${ }^{4}$ This represented the so far most widely used model of pre-retirement work reduction. The scheme is based on a bilateral agreement between employee and employer and required a reduction of working hours by half in the last five years before the public pension is claimed. The remaining "half” working time could be distributed either consistent over the whole period of five years or could be fulfilled entire in the first two and a half years without a reduction in working, the so-called "block model”. In both cases the employee gets an ongoing payment, composed of his part-time work income and a supplementary income of 20 percent by the employer. Additionally, the employer pays pension contributions for 80 percent of the part-time work income. The scheme is subsidized in the sense that the supplementary compensation by the employer is tax exempted (see Börsch-Supan et al., 2015).

\section{Step 2.2 (1997): Closing early retirement schemes and the demographic factor}

In December 1997 a reform package passed the German parliament which (would have) included three crucial components to further increase the sustainability of the Germen pension system. First, the old-age pension because of unemployment and for women were abolished for cohorts born after 1952 (see Figure 7d); second, the pension adjustment indexation formula was amended by a demographic factor which would have adapted the benefit growth to the demographic development; and third, actuarial adjustments were introduced for disability pensions. Other than for the old-age pensions the actuarial adjustments were, however, limited to 10.8 percent and depended on the distance between the claiming of a disability pension and the age 63. Moreover, the pre-adjusted disability pension benefits were enlarged if the act of disability happened before the age of 60 what compensated for a major part of the newly introduced actuarial adjustments. The reform package itself should have become effective in 1999 . However, the 1998 new elected government of Social Democrats and Green Party suspended the second and third component of the reform package (demographic factor and changes to the disability pension) in order to find a more social regulation. For 2000 and 2001 the benefit adjustment was aligned to the inflation rate.

\footnotetext{
${ }^{4}$ For readability reasons we will continue to call this pension scheme old-age pension because of unemployment.
} 


\section{Step 2.3 (2000 till 2001): Toward a genuine multipillar system}

The new government presented the revised pension plan in 2000 and 2001. Regarding the disability pension the new government adopted the plans of the former government. Hence, the introduction of actuarial adjustments combined with an improvement of the disability benefits (see Table 6 and Figure 7e). Additionally, the disability pension's originally composition of pensions owing to vocational disability and “real” disability pensions (BU and EU-Rente) was abolished in favor for a twostep disability pension (partial/full earning incapacity) with strict health tests. Whether a disabled individual is eligible for a partial or full disability pension depends on his maximal working capacity (less than six hours per day for a partial disability pension or less than three hours per day for a full rate disability pension). The new disability pension became effective in $\mathbf{2 0 0 1}$.

In the same year the so called Riester-reforms took place which entailed a major reorganization of the German pension system by converting the formally monolithic pay-as-you-go pension scheme into a genuine multipillar system. Hereto, the pay-as-you-go financed system was partial substituted by a (not mandatory) subsidized private funded system (Riester-Rente). The benefits of the original system were, therefore, gradually reduced in proportion to the maximal subsidized contribution rate of the newly created supplementary pension scheme (see decreasing replacement rates in Table 2). This was done by adding an appropriate component into the pension benefit indexation formula. ${ }^{5}$ The side effect of this rearrangement was that the pay-as-you-go system was relieved. This corresponded with the second aim of the Riester reform to stabilize the contribution rate by reducing the pension level. Actually, the Riester reform law stated that the contribution rate to the public retirement insurance must stay below 20 percent until 2020 and below 22 percent until 2030, while the standard net replacement rate must stay above 67 percent. Failure must precipitate further government actions.

\section{Step 2.4 (2004): Toward Sustainability (sustainability factor)}

It became quickly obvious that the contribution rate thresholds could not be fulfilled without further costcutting measures. As a consequence the Commission for Sustainability in Financing the German Social Insurance Systems was established to develop appropriate reform plans at the end of 2002. In the following year the commission proposed an entire reform package (Commission 2003) with two key components. First, the commission encouraged the government to anchor the statutory eligibility age to the expected change of the life length after retirement. To ensure a real increase in the actual retirement age the reform plan suggested, furthermore, to rise the earliest eligibility ages of all retirement schemes and to introduce higher actuarial fair adjustments. Second, an additional factor for the pension benefit indexation formula

\footnotetext{
${ }^{5}$ The 1989 introduced components in the pension adjustment formula, which anchored benefits to the net wage growth, were, thereby, replaced by a sole consideration of the pension system's contribution rate's growth rate. Due to this, changes in the balance between the fiscal burden of pensions and wages had no longer an influence on the adjustment of the pensions.
} 
was proposed which links the benefits to the systems dependency ratio, called "sustainability factor". ${ }^{6}$ Taking into account the lower bound for the replacement rates this factor will further reduce the pension benefits thus that the contribution rate's thresholds are fulfilled. Most of the commission's proposals, and most significantly the introduction of the sustainability factor, quickly passed the German parliament in 2004. An exception represents the adaptation of the eligibility ages to life expectancy. It was argued that an increase of the retirement age would lead to higher unemployment as it takes jobs away from the young.

Parallel to the pension reform the government passed in 2004 the so called "Hartz reforms" and reorganized the pension taxation. The Hartz reforms replaced, inter alia, the unemployment assistance by the lower so called "unemployment benefit II” (commonly called "HARTZ IV”). Table 3 states the development of the unemployment benefits. Moreover, the pension claims granted while receiving unemployment benefit II were stepwise reduced after 2004 from 16 percent to zero percent of the last income (see Table 4). The duration time of normal unemployment benefits were, furthermore, reduced for older workers from maximal 32 month to 18 month. Both measures made unemployment less attractive as substitute for early old-age and disability pension benefits.

Table 3: Unemployment benefits as percentage of last net income.

\begin{tabular}{cl|cccc} 
& & $1975-1983$ & $1984-1993$ & $1994-2000$ & 2005 \\
\hline \multirow{2}{*}{ ALG } & with children & 68 & 68 & 67 & \\
\cline { 2 - 6 } & without children & 68 & 63 & 60 & \\
\cline { 2 - 6 } ALH & with children & 58 & 58 & 57 & ALH replaced by earning \\
& without children & 58 & 56 & 53 & unrelated ALGII \\
\hline
\end{tabular}

Note:

$\mathrm{ALG}=$ unemployment benefits from the public unemployment insurance;

ALH= unemployment assistance;

ALGII= unemployment benefits II; since 1996 annual reduction of unemployment assistance by 3 percent. Source: Authors' own table.

Table 4: Contribution to public pension system for unemployed as percentage of last gross income.

\begin{tabular}{|llllll} 
until $1978 \quad 1979-1982$ & $1983-1999$ & $2000-2004$ & $2005-2006$ & $2007-2010$ & since 2011
\end{tabular}

\begin{tabular}{l|ccccccc}
\hline ALG & 80 & 100 & 80 & 80 & 80 & 80 & 80 \\
ALH/ALGII & 80 & 100 & 80 & ca. 32 & ca. 16 & ca. 8 & none
\end{tabular}

Note:

ALG= unemployment benefits from the public unemployment insurance;

ALH= unemployment assistance replaced by the unemployment benefits II (ALG II) in 2005;

Paid contributions indicates collected pension claims (earnings point) while unemployed.

Source: Authors' own table.

\footnotetext{
${ }^{6}$ The sustainability factor is to a certain degree similar to the demographic factor of 1997 . However, the demographic factor did only consider the increase of the life expectancy while the sustainability factor considers the development of the ratio between beneficiaries and contributors.
} 
The reorganization of the pension taxation was a consequence to a decision of the Federal Constitutional Court which criticized the different taxation of public pension benefits and the pensions of civil servants (see Börsch-Supan and Quinn, 2015). Until 2004 public pensions were taxed only if they surpassed a quite large allowance. Actually, this applied only to relative few cases. With the new regulations a deferred taxation of pension was introduced. Hence, the contributions to the pension insurance got tax exempted and the pension benefits taxable. To prevent a double taxation the reform included a generous transition period. ${ }^{7}$

\section{Step 2.5 (2007): Toward later retirement ages}

In the end, population ageing remained high on the political agenda and so the yet not implemented reform proposal of the commission, namely the increase of eligibility ages. Finally in $\mathbf{2 0 0 7}$ the then labor secretary Franz Müntefering surprisingly unilaterally announced the increase of the statutory eligibility age similar to the suggestion of the commission by 2 year until 2029 (see Figure $7 \mathrm{~g}$ black and blue line). ${ }^{8}$ Parallel the benchmarks for adjustment free disability pensions should be raised from 63 to 65. Still not realized remained the adoption of the early eligibility scheme (old-age pension for workers with a long service history) to the life expectancy (see Figure $7 \mathrm{~g}$ blue dotted line) as well as the introduction of actuarial fair adjustments (see Table 6 for cohort specific actuarial adjustments).

\section{Phase 3 (2007 to 2016): Reform backlash, the "pension with 63"}

With the 2007 pension reform the process toward a sustainable pension system ended and a phase of moderate reform backlashes followed. This process actually started already within the 2007 pension reform as the decision to increase the statutory eligibility age was watered down by exemptions for those workers who have forty-five years with active contribution payments (see Figure $7 \mathrm{~g}$ orange line). This new type of old-age pensions (“old-age pension for especially long careers") could be claimed at the age 65 or older, but not earlier, even with actuarial adjustments. The next backlash happened 2008 as the duration of unemployment benefits were increased for older workers (older than 57) to 24 month (see Table 5). The so far largest backlash took place in 2014 when among other things the Great Coalition enlarged the group of workers with forty-five years of contributions by watering down the definition of contribution year. Even more significantly, this group of individuals was now granted an adjustment free retirement at the age of 63 (see Figure 7h orange line), called “retirement at 63". The claiming age of 63 increased in parallel to the statutory eligibility age, such that the claiming age for this type of pensions was set to two years before the statutory eligibility age. This type of early retirement became very popular and led to a standstill in the average retirement age which had increased since the turn of the century. Finally, the rigid earning limits

\footnotetext{
${ }^{7}$ The transition included, on the one hand side, an implementation of the tax exemption between 2005 and 2025 and, on the other hand, a constant tax allowances on pension claimed before 2040. The tax exemption increases stepwise from 60 percent to 100 percent. For pension claimed before 2005 the tax allowance was set to 50 percent of the gross pension benefits in 2005. For pensions claimed between 2005 and 2040 the allowance is a fraction of the first received gross pension whereby the fraction itself depends on the pension claiming year and decreases from 50 percent to 0 percent.

${ }^{8}$ Note that the statutory eligibility age was not automatically linked to the life expectancy.
} 
of the partial pension (see 1992 pension reform) were substituted by more flexible limits in 2016, coming into force in July 2017. Within the new system, each additional earned Euro in excess of $6300 €$ per year is only counted by 40 percent towards the pension. The employee can retain 60 percent. With the new regulation the German government tried to encourage partial pensioners to extend their labor supply. However, as actuarial adjustments are still not actuarial fair it has to be shown whether this new regulation will meet their expectation or not.

Even though the most recent process clearly showed a backward movement in the pension policy so far the backlashed reforms were still moderate. The main reform measures for the sustainable pension system remained untouched. However, the current political discussion is at least worrisome as the voices demanding a complete role back become louder.

Table 5: Maximal duration time of unemployment benefits for older workers in months.

\begin{tabular}{l|cccccc} 
Alter\Year & until $\mathbf{1 9 8 5}$ & $\mathbf{1 9 8 5}$ & $\mathbf{1 9 8 6}$ & $\mathbf{1 9 8 7 - 2 0 0 3}$ & $\mathbf{2 0 0 4 - 2 0 0 7}$ & since 2008 \\
\hline $\mathbf{5 1 - 5 5}$ & 12 & 18 & 20 & 26 & & 15 \\
$\mathbf{5 6}$ & & & & & 18 & 18 \\
$\mathbf{5 7}$ & & & 24 & 32 & & 24 \\
$\mathbf{5 8}$ & & & & & & 24 \\
\hline
\end{tabular}

Source: Authors' own table. 
Table 6: Actuarial adjustment factor for early/late pension claiming in percentage by pathway to retirement, pension claiming age and cohort/pension claiming year.

\section{Pension claiming age}

\begin{tabular}{|c|c|c|c|c|c|c|c|c|c|c|c|}
\hline & & 60 & 61 & 62 & 63 & 64 & 65 & 66 & 67 & 68 & 69 \\
\hline \multirow{6}{*}{ 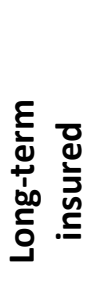 } & Cohort & & & & & & & & & & \\
\hline & $<1937$ & - & - & - & 100 & 100 & 100 & 107.2 & 114.4 & 114.4 & 114.4 \\
\hline & 1937 & - & - & - & 96.4 & 100 & 100 & 106 & 112 & 118 & 124 \\
\hline & $1938-1948$ & - & - & - & 92.8 & 96.4 & 100 & 106 & 112 & 118 & 124 \\
\hline & $1948-1964$ & \multicolumn{10}{|c|}{ stepwise increase of statutory eligibility age } \\
\hline & $>1963$ & - & - & - & 85.6 & 89.2 & 92.8 & 96.4 & 100 & 106 & 112 \\
\hline \multirow{8}{*}{$\begin{array}{l}\frac{c}{0} \\
\frac{5}{0} \\
3\end{array}$} & Cohort & & & & & & & & & & \\
\hline & $<1937$ & 100 & 100 & 100 & 100 & 100 & 100 & 107.2 & 114.4 & 114.4 & 114.4 \\
\hline & 1937-1939 & 100 & 100 & 100 & 100 & 100 & 100 & 106 & 112 & 118 & 124 \\
\hline & 1940 & 96.4 & 100 & 100 & 100 & 100 & 100 & 106 & 112 & 118 & 124 \\
\hline & 1941 & 92.8 & 96.4 & 100 & 100 & 100 & 100 & 106 & 112 & 118 & 124 \\
\hline & 1942 & 89.2 & 92.8 & 96.4 & 100 & 100 & 100 & 106 & 112 & 118 & 124 \\
\hline & 1943 & 85.6 & 89.2 & 92.8 & 96.4 & 100 & 100 & 106 & 112 & 118 & 124 \\
\hline & 1944-1951 & 82 & 85.6 & 89.2 & 92.8 & 96.4 & 100 & 106 & 112 & 118 & 124 \\
\hline \multirow{10}{*}{ 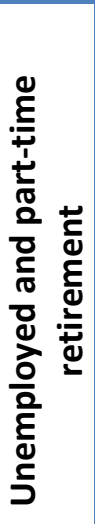 } & Cohort & & & & & & & & & & \\
\hline & $<1937$ & 100 & 100 & 100 & 100 & 100 & 100 & 107.2 & 114.4 & 114.4 & 114.4 \\
\hline & 1937 & 96.4 & 100 & 100 & 100 & 100 & 100 & 106 & 112 & 118 & 124 \\
\hline & 1938 & 92.8 & 96.4 & 100 & 100 & 100 & 100 & 106 & 112 & 118 & 124 \\
\hline & 1939 & 89.2 & 92.8 & 96.4 & 100 & 100 & 100 & 106 & 112 & 118 & 124 \\
\hline & 1940 & 85.6 & 89.2 & 92.8 & 96.4 & 100 & 100 & 106 & 112 & 118 & 124 \\
\hline & 1940-1945 & 82 & 85.6 & 89.2 & 92.8 & 96.4 & 100 & 106 & 112 & 118 & 124 \\
\hline & 1946 & - & 85.6 & 89.2 & 92.8 & 96.4 & 100 & 106 & 112 & 118 & 124 \\
\hline & 1947 & - & - & 89.2 & 92.8 & 96.4 & 100 & 106 & 112 & 118 & 124 \\
\hline & 1948-1951 & - & - & - & 92.8 & 96.4 & 100 & 106 & 112 & 118 & 124 \\
\hline \multirow{8}{*}{$\begin{array}{l}\frac{7}{0} \\
\frac{0}{0} \\
\frac{n}{0} \\
\frac{0}{0}\end{array}$} & Cohort & & & & & & & & & & \\
\hline & $<1937$ & 100 & 100 & 100 & 100 & 100 & 100 & 107.2 & 114.4 & 114.4 & 114.4 \\
\hline & 1937-1940 & 100 & 100 & 100 & 100 & 100 & 100 & 106 & 112 & 118 & 124 \\
\hline & 1941 & 96.4 & 100 & 100 & 100 & 100 & 100 & 106 & 112 & 118 & 124 \\
\hline & 1942 & 92.8 & 96.4 & 100 & 100 & 100 & 100 & 106 & 112 & 118 & 124 \\
\hline & 1943-1947 & 89.2 & 92.8 & 96.4 & 100 & 100 & 100 & 106 & 112 & 118 & 124 \\
\hline & 1948-1964 & \multicolumn{10}{|c|}{ parallel increase of statutory eligibility age and disableds' eligibility age } \\
\hline & $>1963$ & - & - & 89.2 & 92.8 & 96.4 & 100 & 100 & 100 & 106 & 112 \\
\hline \multirow{6}{*}{ 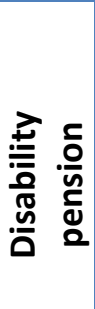 } & Year & & & & & & & & & & \\
\hline & $<1992$ & 100 & 100 & 100 & 100 & 100 & 100 & 107.2 & 114.4 & 114.4 & 114.4 \\
\hline & $1992-2001$ & 100 & 100 & 100 & 100 & 100 & 100 & 106 & 112 & 118 & 124 \\
\hline & 2001-2011 & 89.2 & 92.8 & 96.4 & 100 & 100 & 100 & 106 & 112 & 118 & 124 \\
\hline & $2012-2024$ & \multicolumn{10}{|c|}{ stepwise increase of disability pension's eligibility age and statutory eligibility age } \\
\hline & $>1963$ & - & - & 89.2 & 92.8 & 96.4 & 100 & 100 & 100 & 106 & 112 \\
\hline
\end{tabular}

Source: Authors' own table. 


\section{Figure 7: Eligibility ages with and without actuarial deductions for each pathway to retirement in respect to legal situation.}

Note: The figures summarize three dimensions of policy changes regarding the eligibility age to claim pension benefits: the introduction of actuarial adjustments, the introduction and closure of entire pathways, and finally the gradual increase of the eligibility ages. Each panel a) through h) represents the legal status as seen from a specific year. The horizontal axis displays the time horizon of a worker making a decision about claiming her pension. The vertical axis displays the eligibility age pertaining to the year on the horizontal axis, and the colored graphs represent the pathways with (dotted) and without actuarial deductions (solid). Each panel thus presents the announced future development of the future legal situation. We assume that they correspond to the expectations of workers pondering a claiming decision. Past years are shown in light colors.

a) Legal situation until 1989

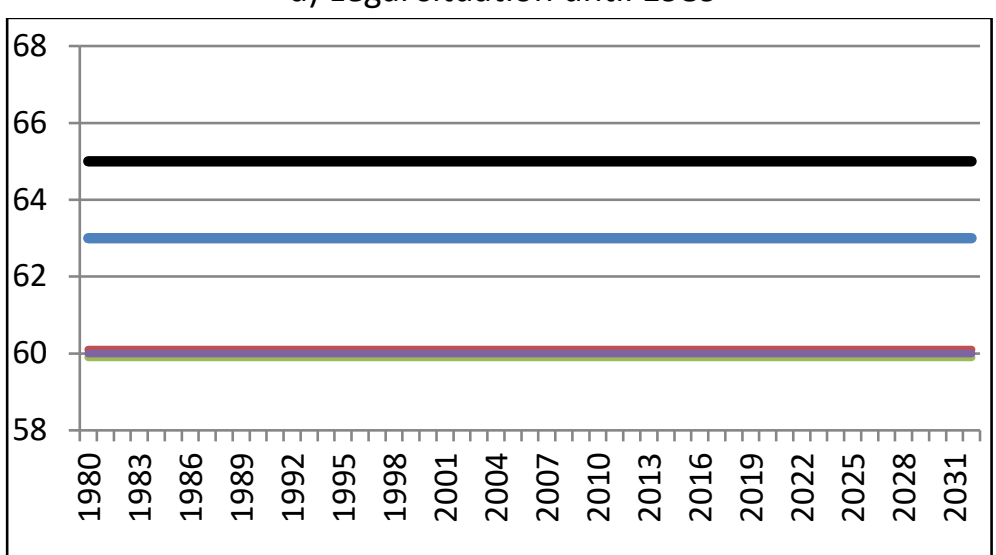

c) Legal situation between 1996 and 1997

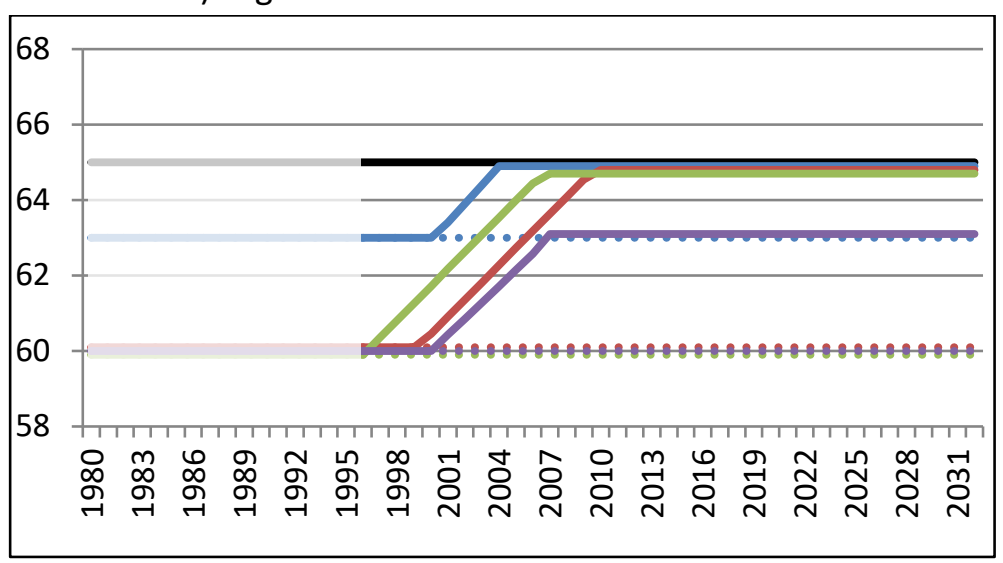

b) Legal situation between 1989 and 1996

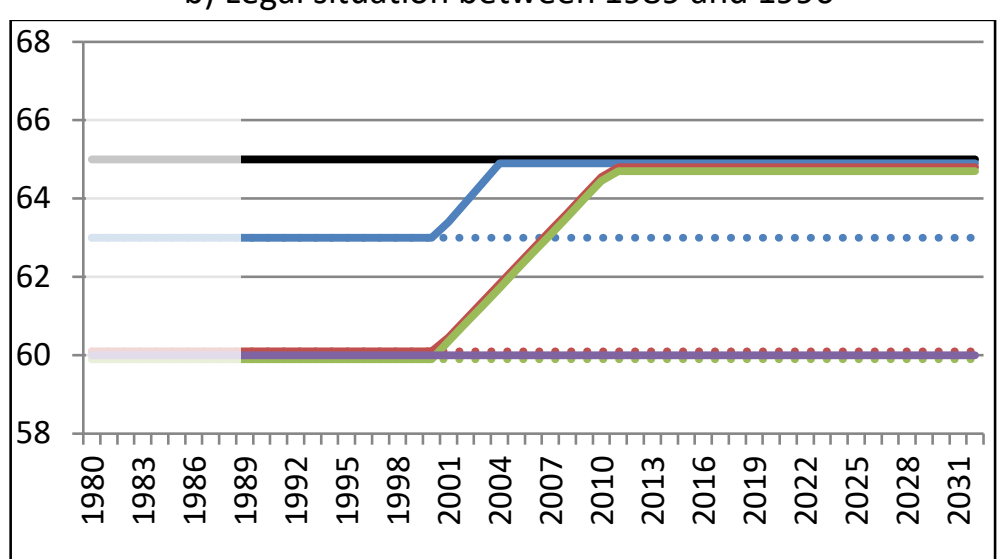

d) Legal situation between 1997 and 2000

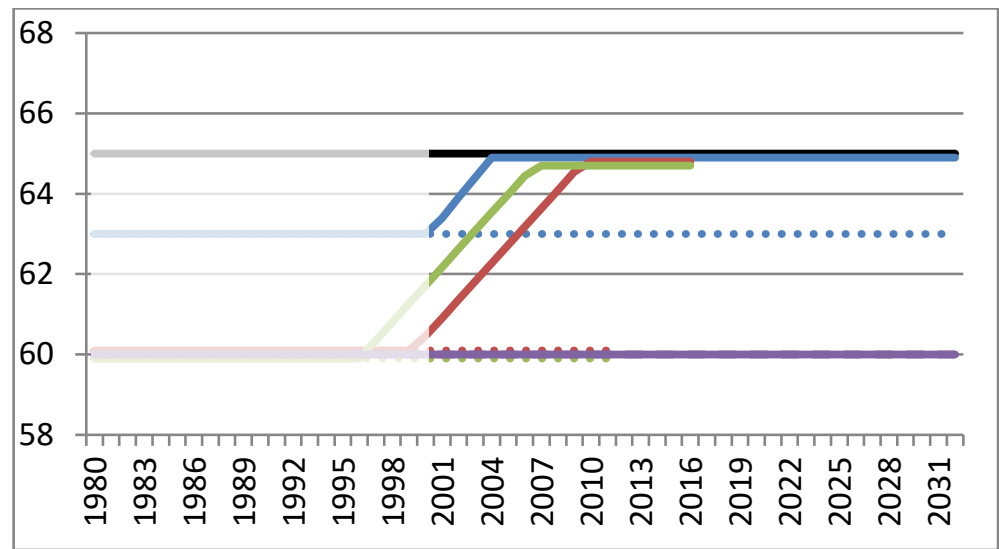


e) Legal situation between 2000 and 2004

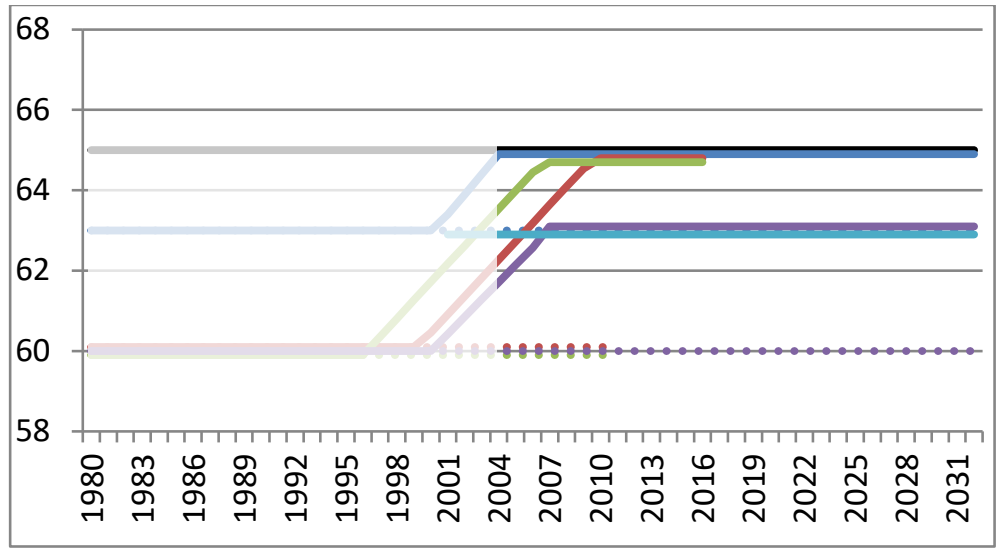

g) Legal situation between 2007 and 2014

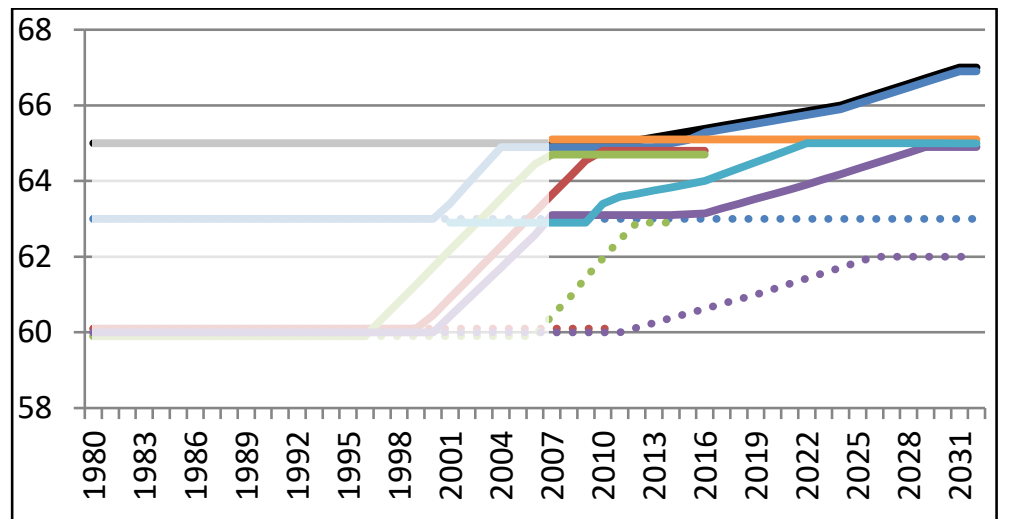

\begin{tabular}{|l}
\hline Regular Old-Age Pension \\
Long-term insured 35+ (without adjustment) \\
Women (without adjustment) \\
Unemployed (without adjustment) \\
Disabled (without adjustments)
\end{tabular}

Source: Authors' own diagram.

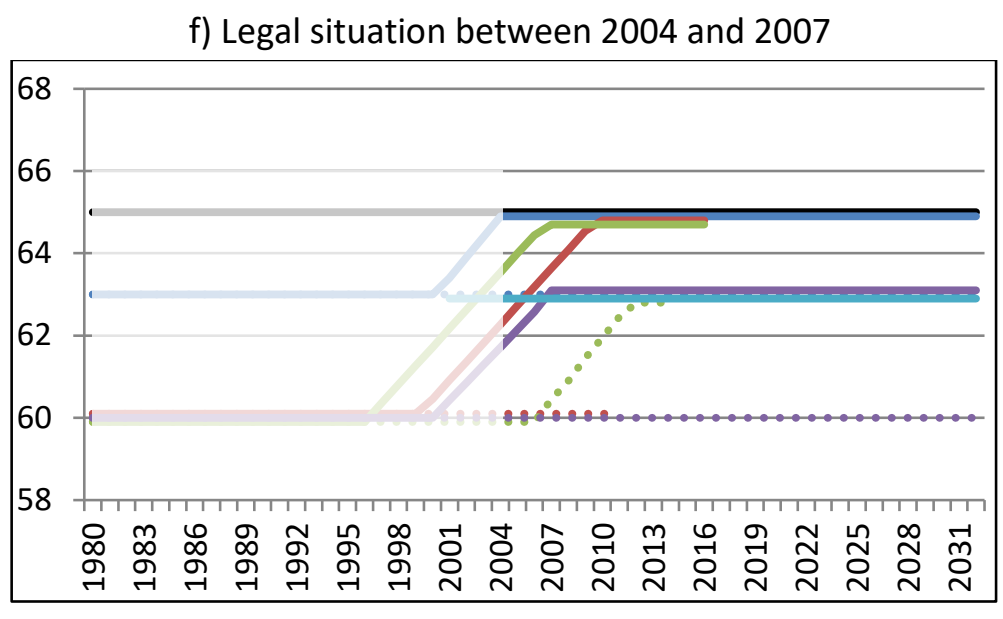

h) Legal situation since 2014

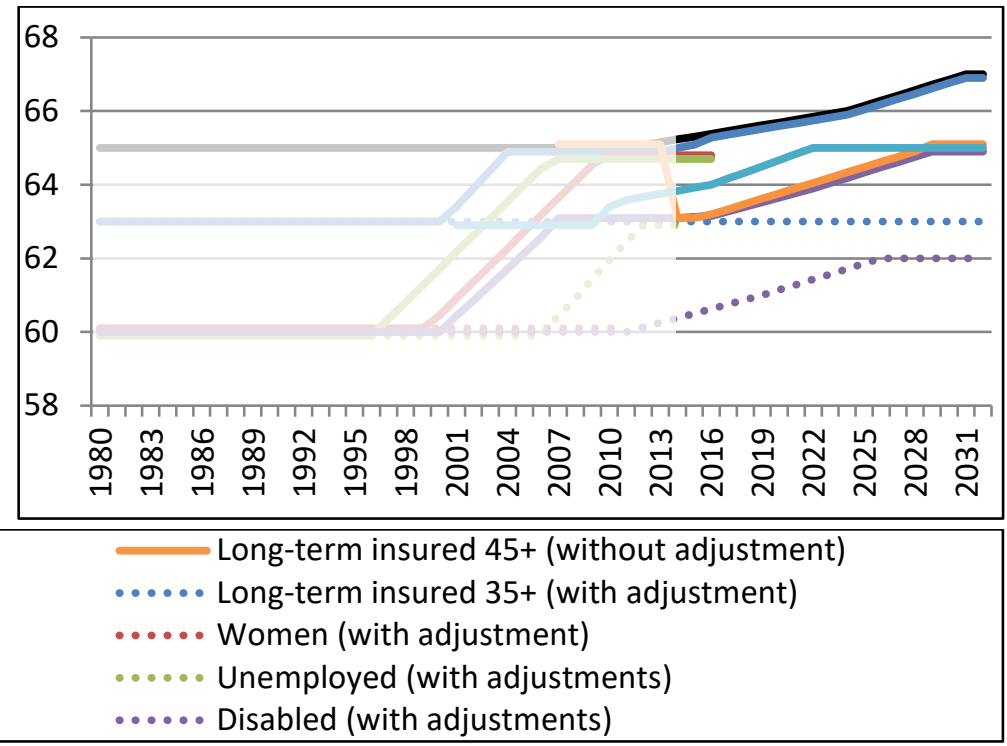




\section{The implicit tax on working longer}

\section{Definition}

As described in the previous sections, the German retirement insurance creates strong incentives to claim a pension and exit the labor force relatively early in life through a variety of mechanisms. These mechanisms can be summarized compactly in terms of a loss in social security wealth when postponing claiming and retiring from the labor force. Since Germany applies a relatively strict earnings test for ages below the normal eligibility age, claiming a pension invariable implies leaving the labor force at those younger ages, and we simply refer to “retiring” for this joint decision.

Social security wealth is the expected net present value of social security benefits minus contributions to the public pension and unemployment insurance during the retirement window, here defined as the age range from fifty-five through sixty-nine. Contributions before age fifty-five are sunk. Future contributions and benefits depend on the legal situation $l$ at the planning age $S$ and the used pathway to retirement $k$ (e.g. via unemployment or disability pension). Seen from the perspective of a worker who is $S$ years old and plans to retire at age $R$ social security wealth is given by:

$$
S S W_{S, k, l}(R, i)=\sum_{t=R}^{T} B_{t, k, l}(R, i) \cdot \sigma(i)_{S, t} \cdot \beta^{t-S}-\sum_{t=S}^{R-1} c_{t, l} \cdot Y_{t}(i) \cdot \sigma(\mathrm{i})_{S, t} \cdot \beta^{t-S}
$$

with

SSW: $\quad$ net present discounted value of retirement/unemployment benefits

$S: \quad$ planning age

$R: \quad$ benefit claiming age

$i$ : $\quad$ gender and skill type

$k$ : $\quad$ pathway to retirement

$l$ : legal situation at planning age $S$

$Y_{t}(i)$ : $\quad$ gross labor income at age $t$

$B_{t, k, l}(R, i)$ : net benefits from pathway $k$ at age $t$ for benefit claiming age $R$ and legal situation 1

$c_{t, l}: \quad \quad \quad$ contribution rate to pension and unemployment system at age $t$ for legal situation $\mathrm{l}$

$\sigma(i)_{S, t}: \quad$ probability to survive at least until age $t$ given survival until age $S$

$\beta$ : $\quad$ discount factor $\delta=1 /(1+r)$. We choose the usual discount rate $r$ of 3 percent.

Postponing retirement by one year has two negative effects on social security wealth: the worker must give up one year of (net) pensions, and he must continue to pay contributions to the pension system of about 10 percent of his gross earnings. On the other hand, postponing retirement raises pension benefits due to these additional contributions by roughly one-fortieth and due to the actuarial adjustments by 3.6 percent per year of postponement (after the 1992 reform has been fully phased in).

The incentives to leave the labor market and claim a pension can be expressed conveniently by the implicit taxes which are based on the accrual of social security wealth. In this study, accrual is defined as the expected gain in social security wealth by postponing the labor market exit by one year. The implicit tax is 
the negative accrual of social security wealth $(A C C)$ divided by the after tax earnings $\left(Y^{\text {Net }}\right)$ during the additional year of work:

$$
I T A X=-\frac{A C C}{Y^{N e t}}
$$

As long as the implicit tax is negative, it is rational to postpone the withdrawal from the labor market unless labor/leisure preferences or similar considerations dominate the expected gain in social security wealth. Negative implicit taxes from a certain age on are sufficient (although not necessary) for leaving the labor market and claiming a pension at that age.

\section{Empirical implementation}

We compute the accrual of social security wealth and the implicit taxes for each year between 1980 and 2016. Individuals are assumed to anticipate the future development of the contribution rates and pension benefits based on the legal situation of the planning year $S$ according to Figure 7 . We do not expect that individuals anticipate future reforms. For the past, the pension system's contribution rates and replacement rates are estimated for each relevant legal situation on the basis of historical data. For the future, we predict the development of the German public pension system's key parameters for each reform stage separately with the simulation model MEA-PENSIM (see Holthausen et al., 2012). The (future) pension benefits depend on the earning history of the individual, the chosen pension claiming age/pathway to retirement (actuarial adjustments, unemployment benefits) and the future replacement rate (pension value). The last two components may change with pension reforms.

We compute social security wealth, its accrual and the implicit tax on working longer for 18 idealized constellations. We distinguish 3 gender groups (single female, single male, couple), 3 skill groups (low, medium and high education/skill) and 2 macro environments (common environment across all 12 countries involved in the ISSP, German environment). For each of these 18 idealized constellations, we construct a matrix of 38x15 values (i.e, social security wealth, its accrual and the implicit tax) where the 38 rows refer to the years of the time series (1980 to 2016) and the 15 columns refer to the claiming ages $S$ (55 to 69 ). Moreover, each value is based on separate computations for each 6 pathways which are then aggregated using as weights the frequency for each pathway.

In more detail, we calculate social security wealth for gender specific synthetic income profiles of low, medium and high education/skilled single households. Low skilled are expected to enter the labor market with 16, medium skilled with 20 and high educated with 25. For couples, we assume a rather simple case: a male (female) who is married to a partner 3 years younger (older) of the same skill /education type. We assume furthermore that the spouse's retirement behavior is fixed, i.e., it will not react to the partner's retirement decision.

The macro environment is represented by assumptions on (a) the age-earnings profile, (b) the payroll taxation including social security contributions and (c) age and gender-specific survival probabilities. We 
specify a common synthetic environment in order to avoid confounding cross-national differences in pension policy with other determinants of social security wealth such as different age-earnings profiles, different taxation and different survival probabilities. More specifically:

\section{a) Common macro environment:}

Common synthetic earnings profiles for the three skill/education groups are calculated with data from the USA, Germany and Italy. ${ }^{9}$ They are depicted in Figure 8 (dotted lines).

Common survival rates for 2010 were provided by Eurostat (average of EU28 countries). The underlying life expectancy at age 15 is 67.8 years for women and 64.7 year for men. For men the life tables are adjusted to generate life expectancies which are 2/4 year higher/lower to reflect the higher/lower life expectancy of high/low educated men. Similar the life tables for women are adjusted, however, here it is assumed that low educated women have a 4.5 lower life expectancy. Common payroll taxes are taken from the OECD tax data base (see OECD, 2018b) and refer to all income taxes and employee and employer social security contributions.

b) National macro environment:

In order to compare the actual German retirement behavior with the prevailing implicit taxes, we calculate implicit taxes for German earning profiles, life tables and payroll taxes. The earnings profiles are calculated with administrative data of the German pension insurance (SUF-VSKT 2011, see DRV, 2011). For women we find only small difference between the income profiles of younger and older cohorts. As a consequence we consider cohort specific incomes profiles only for men. The average income profiles are depicted in Figure 8.

The cohort specific life tables are provided by the German Federal Statistical Office in Statistisches Bundesamt (2015). Similar to the common cases we adjusted the life tables for high/low educated individuals in order to control for the differences in life expectancy.

In terms of taxes, we use our own tax calculator which calculates the tax rate accordingly to the prevailing legal situation. To illustrate the influence of the stepwise introduced deferred taxation, we show additionally results which exclude this reform.

\footnotetext{
${ }^{9}$ The data sources are the US Current Population Survey (CPS) and administrative data from the German and Italian pension system (SUF-VSKT 2011, see DRV 2011 and INPS).
} 
Figure 8: Pension claiming by age and year (1985-2015) in West Germany.
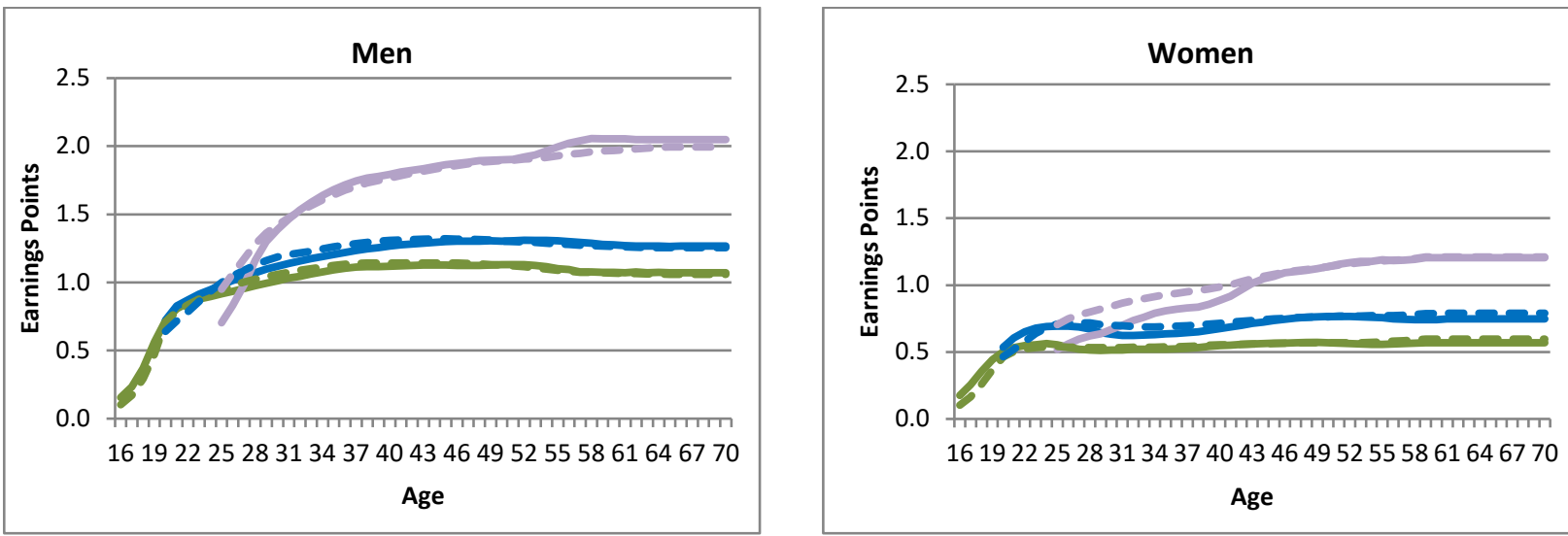

\begin{tabular}{|ccc}
\hline Germany Low educated & Germany Medium educated & Germany High educated \\
$-\infty$ & International Low educated & - International Medium educated
\end{tabular}

Source: Authors' own calculations based on US Current Population Survey (CPS), German SUF-VSKT 2011 (DRV, 2011) and Italian INPS.

The matrices of outcome values are aggregated over 6 pathways:

- Regular old-age pension (at the statutory eligibility age),

- Early pension claiming via old-age pension for long-term insured or for women,

- Leaving the labor market via unemployment,

- Part-time employment prior to retirement,

- Early pension claiming via old-age pension for disabled, and

- Disability pension.

It is important to notice that all of these pathways pay the same benefit once a person is eligible. They differ, however, by their eligibility criteria (see Table 1). Among those, "strict" and "soft" eligibility rules can be distinguished. The first are tied to objective variables, such as age, gender, and previous contribution history while the second are subject to discretionary decisions, notably the determination of a workers' disability status.

The conditions for the various retirement programs are in our case, however, only relevant to a certain degree since the social security wealth is computed for synthetic individuals. As a consequence, we calculate the social security wealth for each pathway separately and aggregate the resulting implicit taxes afterwards by weighting them with the observed frequency of the corresponding pathway among all pension claims. We assume, accordingly, that the actual distribution of the various pathways reflects the probability to fulfill the eligibility requirements of the respective pathways. These probabilities vary between the group of insured individuals and the subgroup of insured individuals who did not drop out of the labor market at younger ages. We therefore consider two different weighting approaches. The first approach uses the distribution of the pathways on all public pension claims as depicted in Figure 4. The second approach considers the distribution of the pension claims of those individuals only who paid contributions in the year 
before they claimed their pension (see Figure 9). This second approach excludes "passively insured" individuals (e.g. homemakers).

This alternative frequency is used if the implicit taxes should be compared with the employment rate. Essentially, we aim to exclude those effects on the frequency which derived from insured individuals who do not belong to the labor market before claiming the public pension (e.g. homemakers). Actually, the 1985 shift in the balance between regular old-age pensions and disability pensions is much smaller under this approach (compare Figure 9 with Figure 4). The annual frequencies are used to combine the implicit taxes with the same labor exit ages. By definition these are the implicit taxes with the same planning age $S$. In the following, this approach represents our basic weighing procedure.

\section{Figure 9: Coverage of pathways to retirement on annual newly claimed pensions without passively insured individuals.}

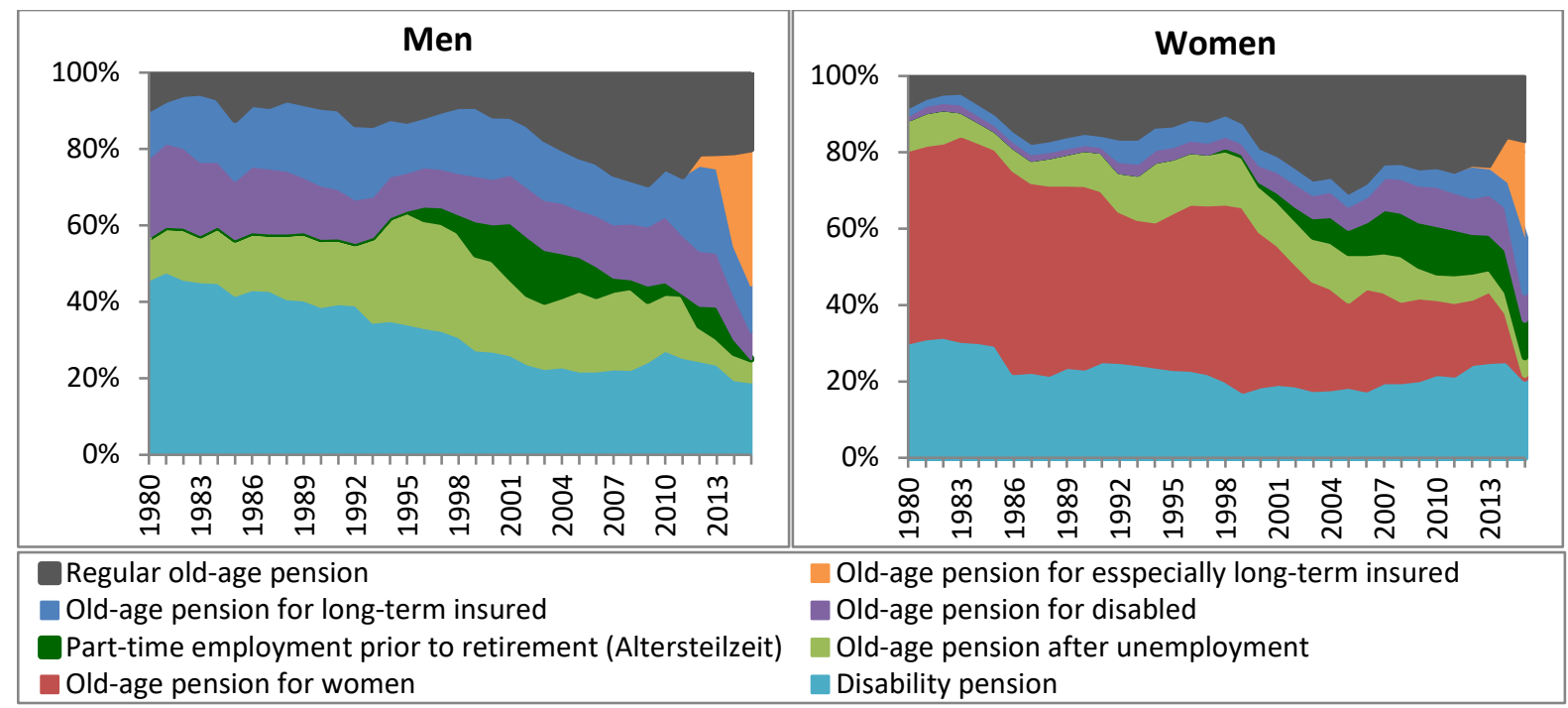

Source: Authors' own calculations based on Deutsche Rentenversicherung Bund (2017),

Rentenzugangsstatistik.

The frequencies displayed in Figure 4 are used only when the implicit taxes are compared with the development in the overall pension claiming behavior. Under this approach the implicit taxes with the same underlying pension claiming age have to be combined. For most cases these are again the implicit taxes with the same planning age $S$. Exceptions are the pathways via unemployment and part-time work. Here, the pension claiming age is later than the labor exit age: for the unemployment pathways one or two years (depending on the maximal duration of unemployment benefits) and for the pre-retirement pathway via part-time work (by assumption) up to 5 years. 


\section{Results}

In the following, we will present the results of our calculations in a stepwise fashion. Subsection 5.1 presents individualized replacement rates and social security wealth, i.e., the elements from which the implicit tax will be computed, on a scale more often used in the economics literature than the Germanspecific "standardized replacement rates" in Section 3 (Table 2). For comparability, we apply the German payroll taxes.

In Subsection 5.2, we introduce the common macro environment. We first present general outcome variables such as replacement rate, social security wealth and its accrual. Subsection 5.3 follows with the implicit tax on working longer for median educated men, women and couples. Subsection 5.4 shows how these implicit taxes vary between different skill groups.

Subsection 5.5 uses the differences between the common environment and the national case for a discussion how the implicit taxes depend on specific national taxation, income profiles and life tables.

Finally, subsections 5.6 and 5.7 are devoted to a graphical juxtaposition of our computed implicit taxes with the actual development of employment and the changes in the distribution of the pension claiming age. A formal multivariate regression analysis is the aim of a subsequent phase of the ISSP.

\subsection{Replacement rates and social security wealth, scaled for Germany}

\section{Replacement rate}

The standardized replacement rates shown in Table 2 of a pensioner with constant average earnings over the entire work life do not reflect actual earnings profiles which typically increase with age. Moreover, these standardized replacement rates do not take the introduction of the deferred taxation on pension benefits into account. As a consequence, we analyze in the following individualized net replacement rates (pension benefits as share of last earnings by the types of individuals and households defined in the previous section) which were computed in the calculation process of the implicit taxes.

In order to maintain some comparability to the official German figures, the calculations in this subsection are based on the tax rate calculations of the German macro environment (see section 4) but use the income profiles and survival probabilities of the common macro environment. The most critical difference is the fact that the common taxation does not only tax labor income but also pension income although German public pension benefits were not taxed until 2005. The common taxation therefore leads to much smaller net replacement rates than it was actually the case. The net replacement rates are depicted in Figure 10 for median educated men, women and couples at the planning age 60 to 64 between 1980 and 2016. In the couples case the replacement rate is shown from the men's perspective while the women's claiming age is three years younger. 
First of all, we observe in all cases nearly constant replacement rates until 2004. The smaller fluctuations result from changes in the tax rates on the last labor income. As shown in Subsection 5.2, these fluctuations do not appear in the case of common tax rates. After 2004, both the standardized replacement rates (Table 2) and the individualized net replacement rates decrease. This is due to the introduction of the sustainability factor. The decrease, however, is more moderate for the standardized replacement rates, especially for men. This steeper decrease is due to the stepwise introduction of the deferred taxation since the increasing taxation reduces the net pension benefits additionally to the sustainability factor.

Figure 10: Replacement rate for median educated men, women and couples by age.

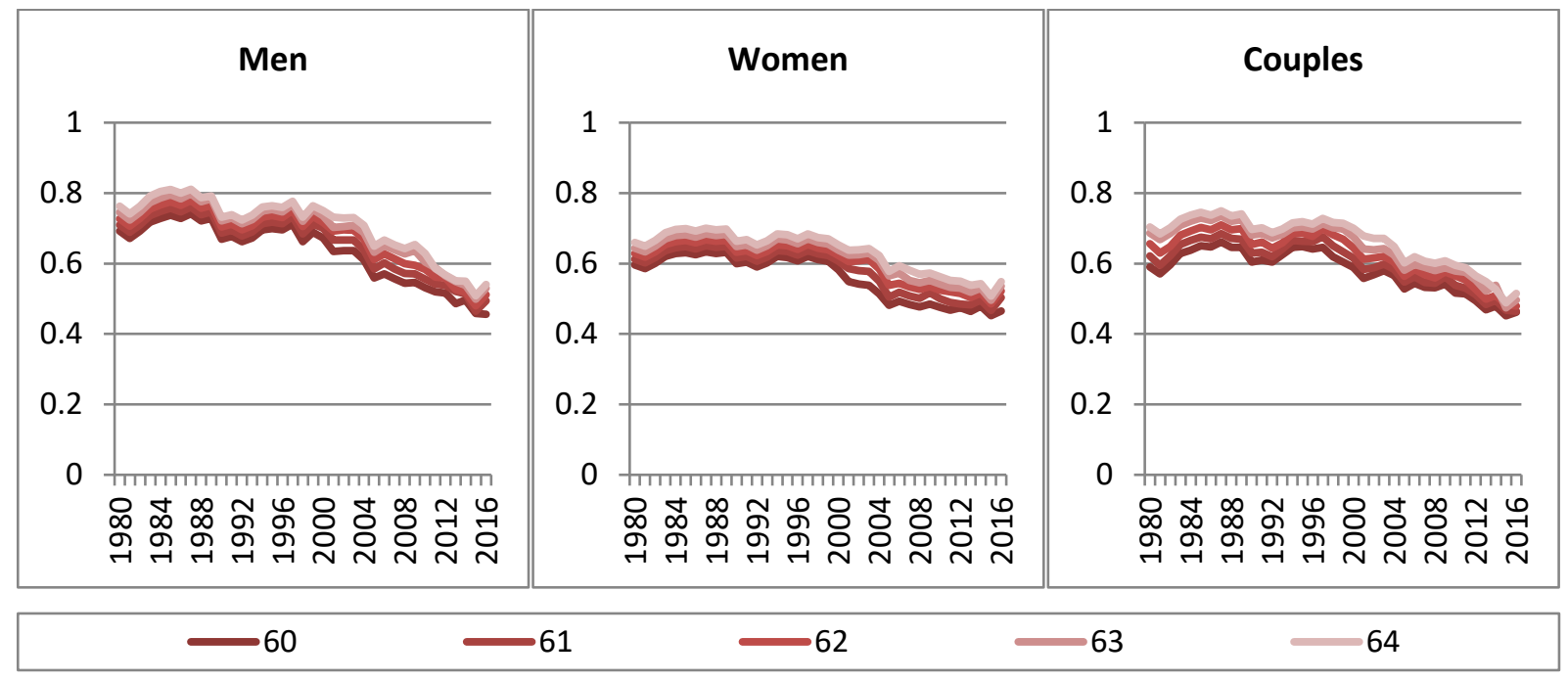

Source: Authors' own calculations.

The individualized replacement rates increase with age since individuals earn additional pension claims while their labor income remains constant at older ages. Moreover, we observe in the past higher replacement rate's for men than for women. This is due to lower taxation of women's last labor income, hence due to the progressivity of the tax system, and the now past tax exemption for public pension benefits. As a consequence, the gap disappeared in recent years due to the abolishment of the tax exemption for public pension benefits (i.e., introduction of the deferred taxation). Moreover, the progressivity of the tax system has led to a larger reduction of high pensions benefits (typically men) than for small pension benefits (typically women). As the replacement rates of couples is a product of the spouses replacement rates they lie somewhere between the replacement rate of single men and women and have a similar development.

Higher skilled individuals have smaller replacement rates than less/median educated individuals (see Figure 11). The replacement rates of higher educated individuals are lower due the higher share of their last income on their life time income. This is mainly a result from the shorter labor history of higher educated individuals. Lower and median educated individuals accumulated, on the other hand, their pension claims over a longer time period such that their pension benefits a less strongly linked to their last income. There is a similar but smaller divergence between low and median educated individuals. 
Figure 11: Average replacement rate of age group 60-64 by education group.

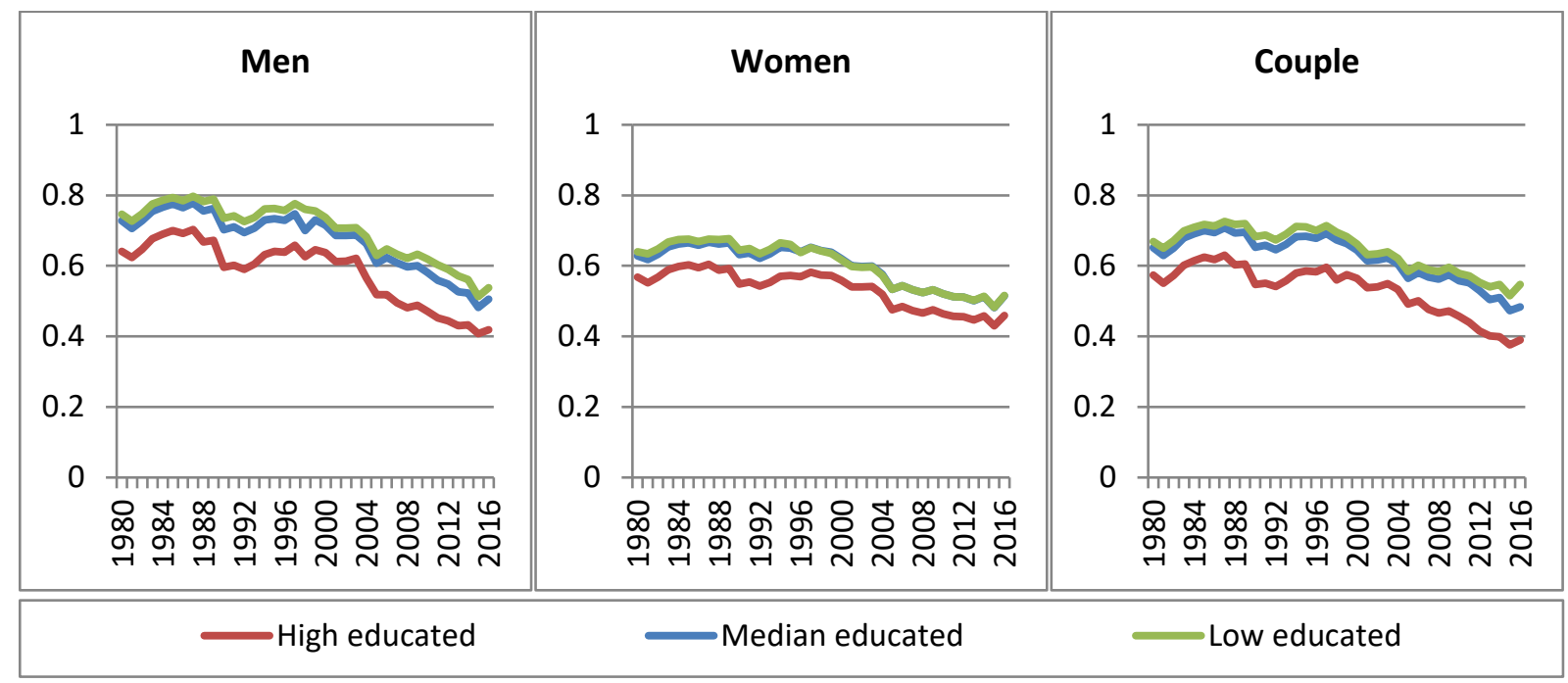

Source: Authors' own calculations.

\section{Social Security wealth}

Figure 12 depicts the social security wealth that would be attained if the worker were to leave the labor market and claim a pension immediately. As before, it is based on common earnings profiles, common survival probabilities but German tax rates, and the figures show median educated single men, single women and couples at claiming ages between 60 to 64 years. The level of social security wealth depends on life time income; hence men's social security wealth is larger than women's. Social security wealth increased for all groups between 1980 and 1996. The growth rate reflects the annual pension increase which was first anchored to the average gross wage and after 1989 to the average net wage. After 1996 the increasing trend was reduced by the implementation of different reforms. The strongest effect had the introduction of actuarial deductions for early retirement. Before their introduction, social security wealth increased only marginally with the claiming age. ${ }^{10}$ This changed afterwards since the actuarial deduction reduced the social security wealth (pension benefits) of younger claiming ages/pension claiming ages. This led to gaps between the social security wealth of different claiming ages.

Moreover, there were two reforms which reduced the social security wealth in general: first, the introduction of the demographic factor in 1998 which was later replaced by the sustainability factor and second, the introduction of the deferred taxation. The influence of the deferred taxation depended, however, on the amount of the pension income. The social security wealth of pensioners with higher benefits (e.g. highly educated men, see Figure 13) dropped stronger than those with low benefits. At last, the growth rate of the social security wealth decreased or even disappears after 2005 for those groups with higher pension benefits, again due to the stepwise introduction of deferred taxation.

\footnotetext{
${ }^{10}$ It is important to not mix up this with the incentive to postpone the labor market exit. For instance, remember that previous contributions to the social security system are sunk at a given plaining age but not the further contribution.
} 
Couples' social security wealth results from the spouse's social security wealth and the possibility of receiving a survivor's pension. As a consequence, couples' social security wealth is larger than the sum of the social security wealth of a single men and women.

The social security wealth increases with the skill level (see Figure 13) since higher educated individuals have both larger pension claims and a higher life expectancy, thus a longer expected duration of pension benefits.

Figure 12: Median educated men's, women's and couple's social security wealth of leaving the labor market immediately in 1000 Euro by age.

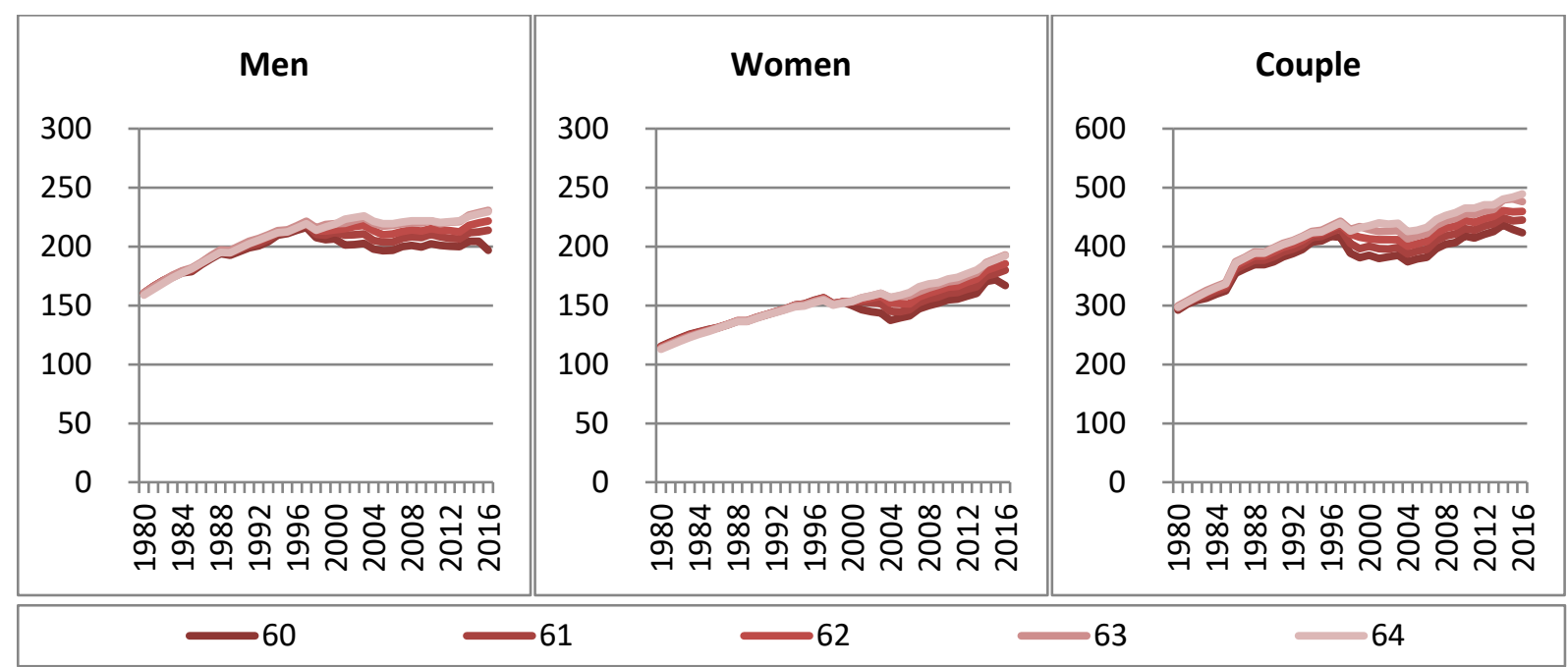

Source: Authors' own calculations.

Figure 13: Average social security wealth of age group 60-64 in 1000 Euro by education.

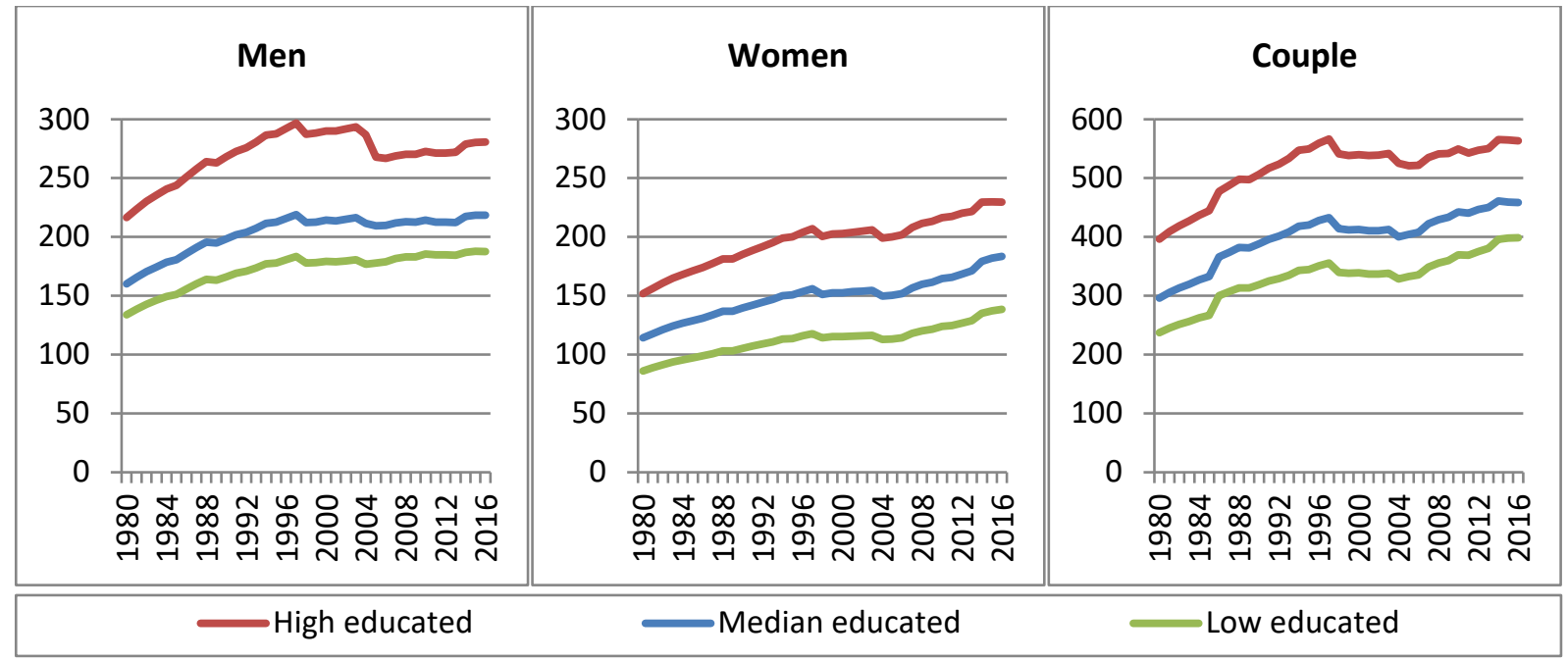

Source: Authors' own calculations. 


\subsection{Common macro environment: Replacement rates, social security wealth and its accrual}

\section{Replacement rate}

As a next step, we apply common taxation in order to maintain comparability across all countries involved in the project.

The respective net replacement rates are depicted in Figure 14. Due to the taxation of the pension benefits the replacement rates are much smaller than the replacement rates in Figure 10. Moreover, the development of the replacement rates under the common case assumptions is less volatile since the fluctuations caused by the changes in the time-specific German tax rates are smoothened. The decrease in the replacement rates is, moreover, less pronounced since the taxation of the pension benefits has led to a smaller influence of marginal changes in the pension level on the replacement rate.

Figure 14: Replacement rate for median educated men, women and couples by age (Common case).

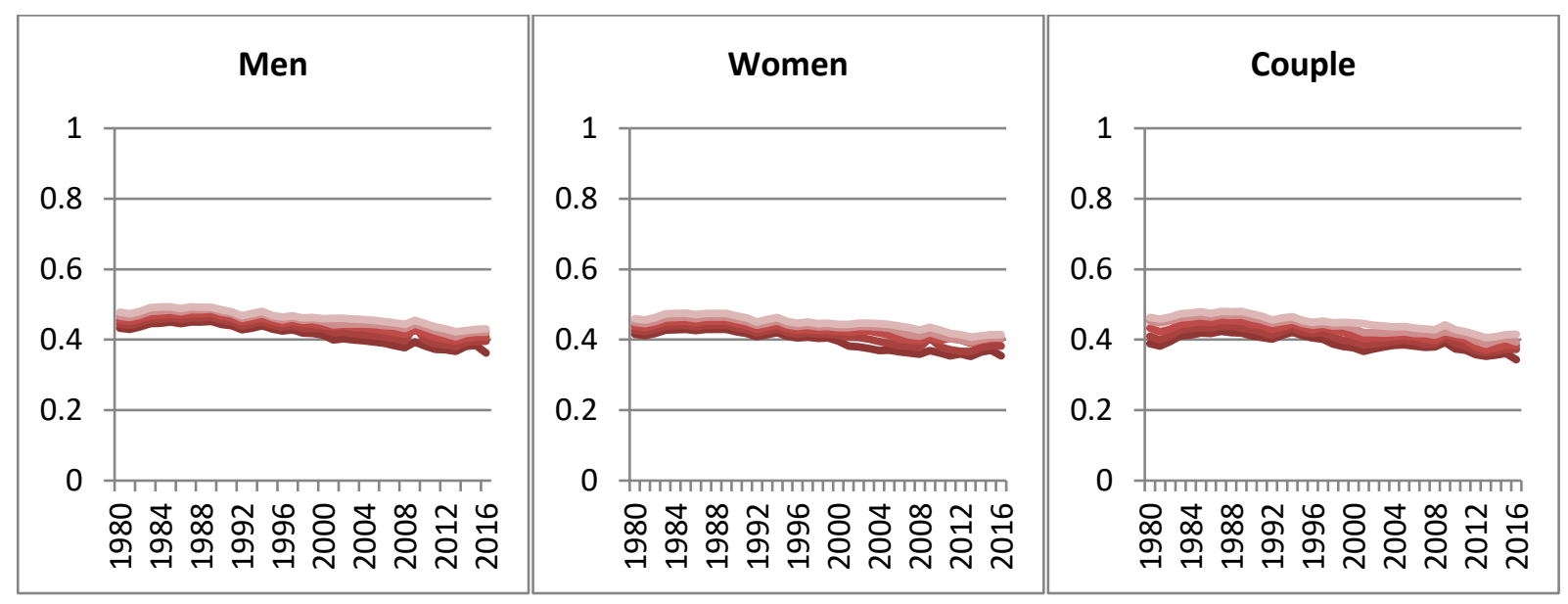

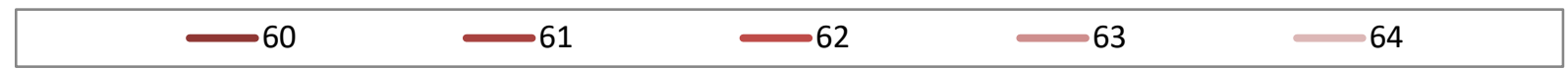

Source: Authors' own calculations. 
Figure 15: Average replacement rate of age group 60-64 by education group (Common case).

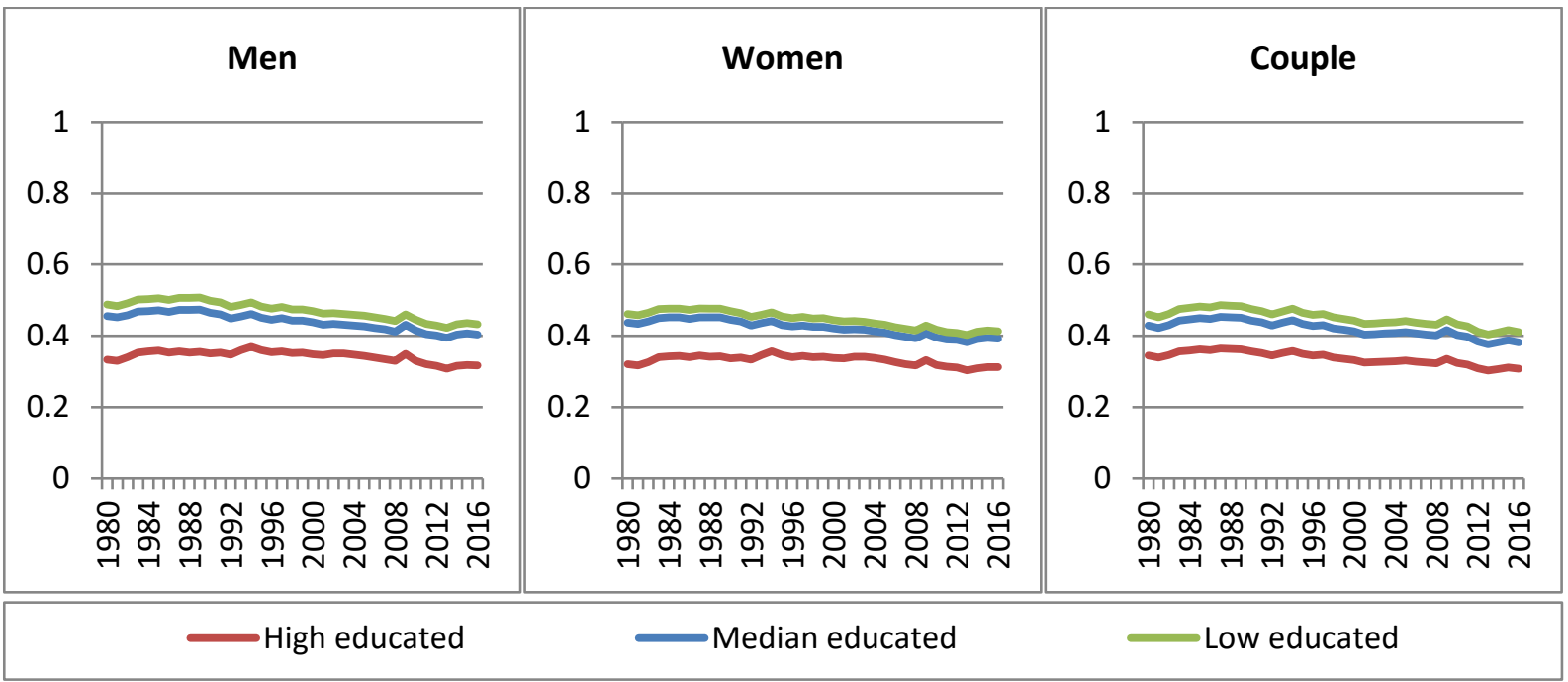

Source: Authors' own calculations.

\section{Social Security wealth}

Figure 16 depicts the social security wealth of leaving the labor market immediately, now for the common case. Social security wealth is smaller in the common case since the OECD tax rates are considerable larger. Also the dynamics change: social security wealth increases after 2004 for both men and couples. This shows that the more or less constant social security wealth under German taxation is mainly a result of the introduction of the deferred taxation.

Figure 16: Median educated men's, women's and couple's social security wealth of leaving the labor market immediately in 1000 Euro by age (Common case).

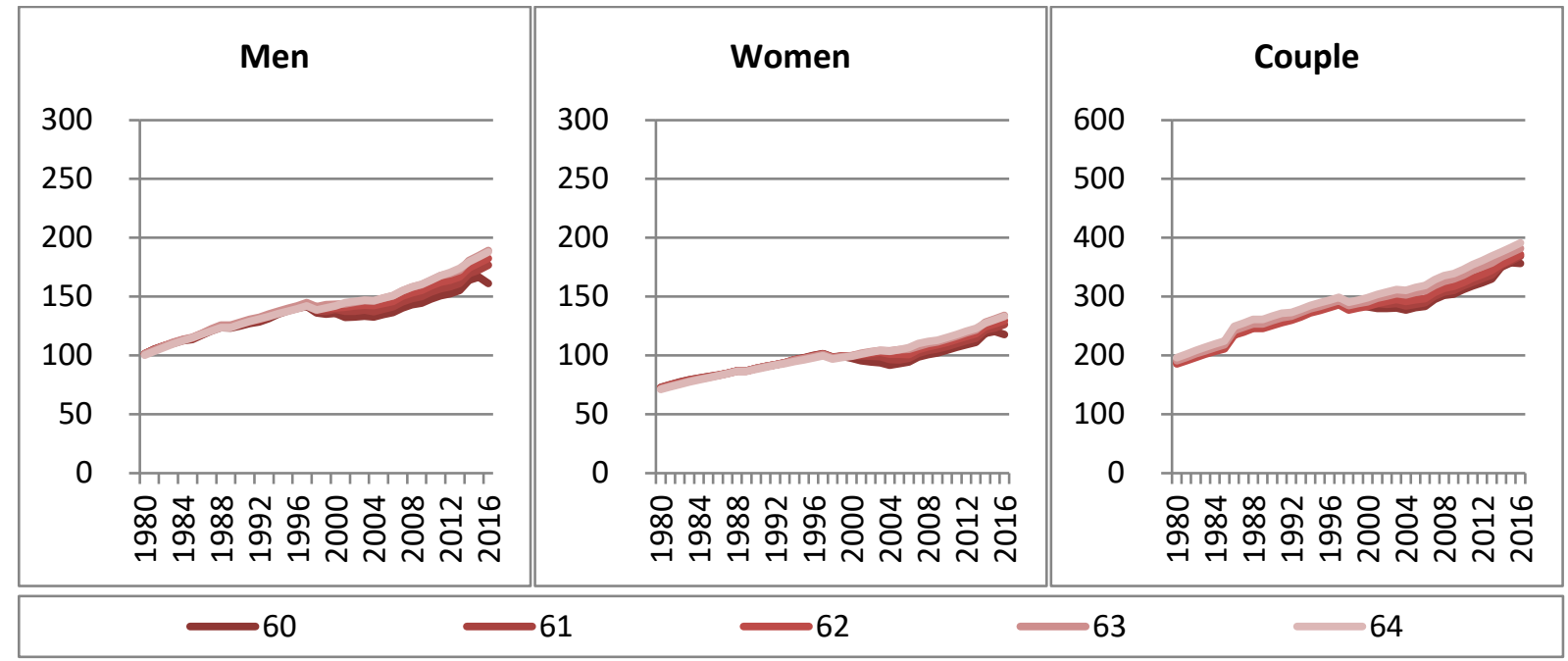

Source: Authors' own calculations. 
Figure 17: Average social security wealth of age group 60-64 in 1000 Euro by education (Common case).

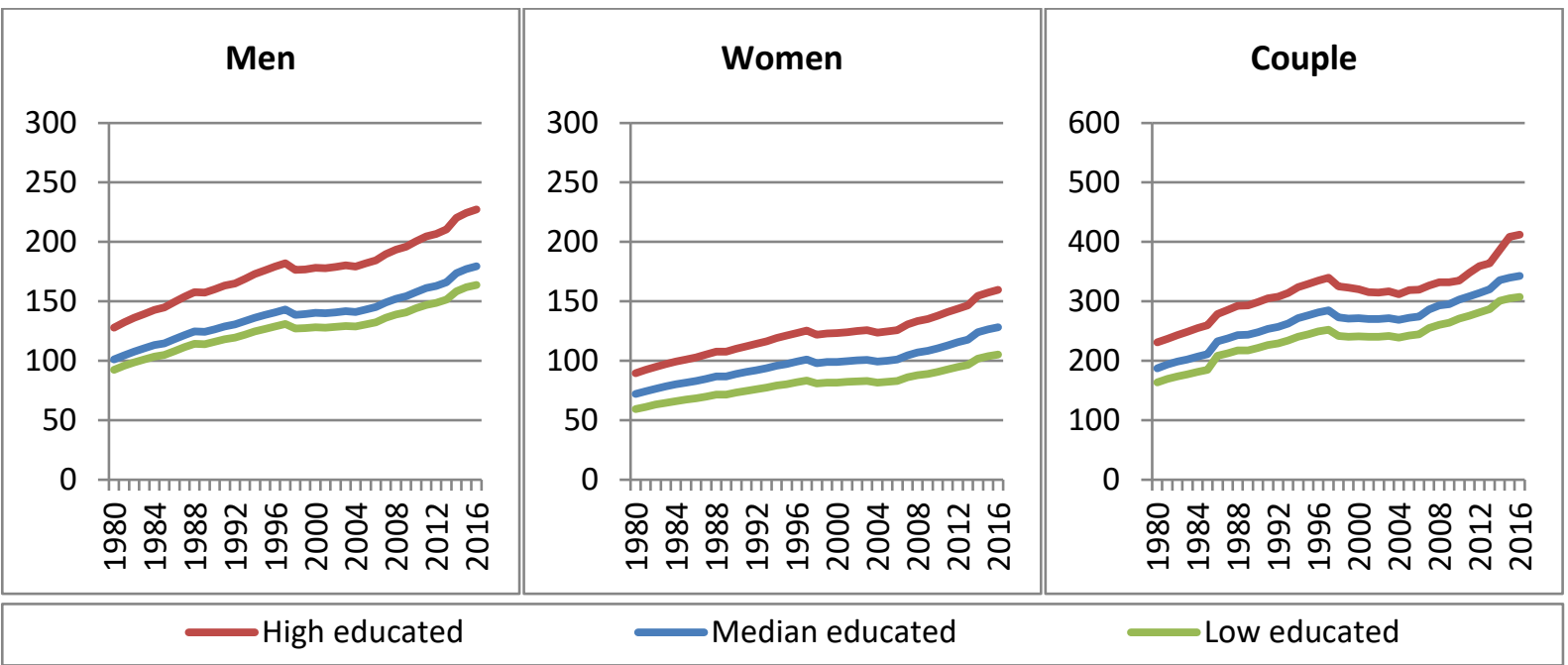

Source: Authors' own calculations.

\section{Accrual rates}

We define the accrual of social security wealth as the change in social security wealth that workers expect when they postpone claiming benefits by one year. It is the numerator of the implicit tax on working longer as defined in Section 4.

Figure 18 shows the accrual for median educated single men, single women and couples while Figure 19 studies the variation by education/skill group. It is reported here for completeness and comparability to the other country chapters. Since the accrual is qualitatively very similar to the implicit taxes, we relegate a detailed description to the following subsection.

Figure 18: Median educated men's, women's and couple's accrual of social security wealth of leaving the labor market immediately in 1000 Euro by age (Common case).

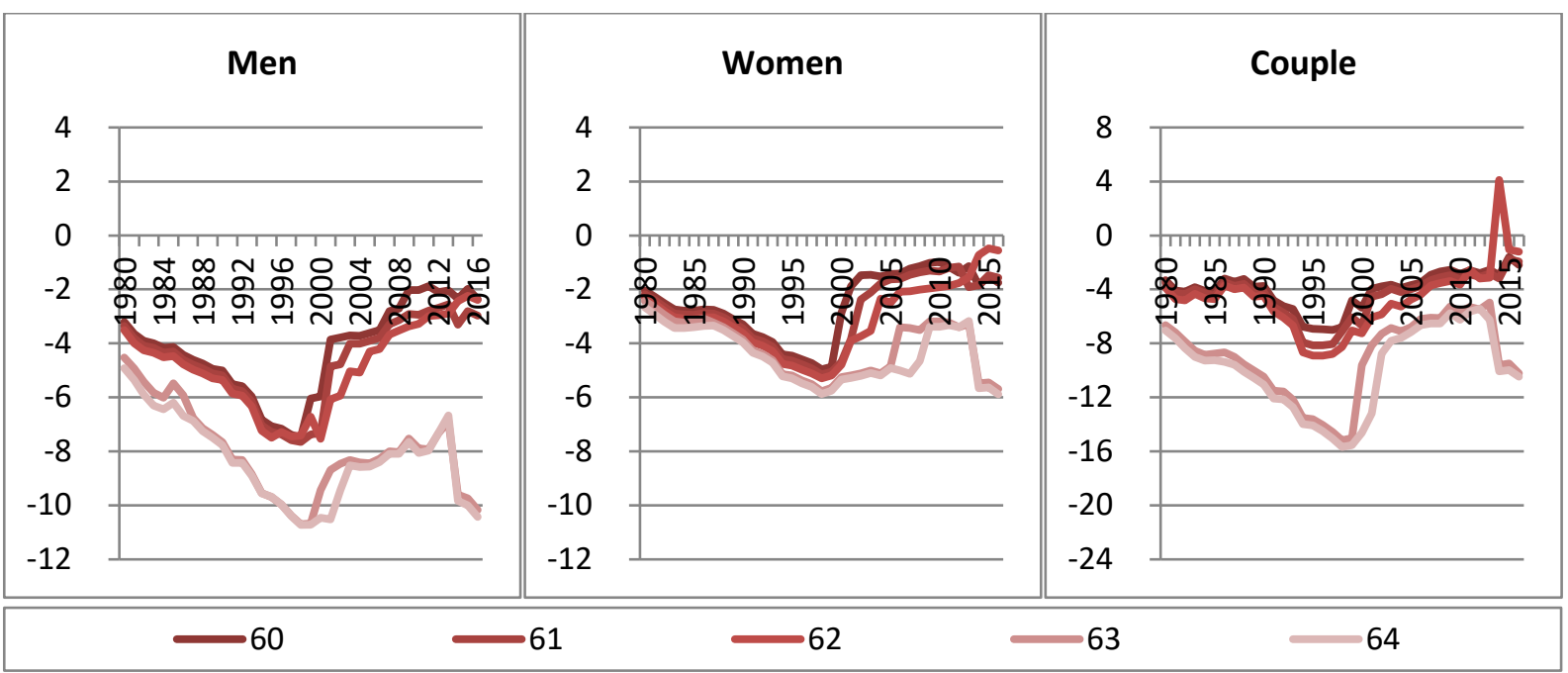

Source: Authors' own calculations. 


\section{Figure 19: Average accrual of social security wealth of age group 60-64 in 1000 Euro by education (Common case).}

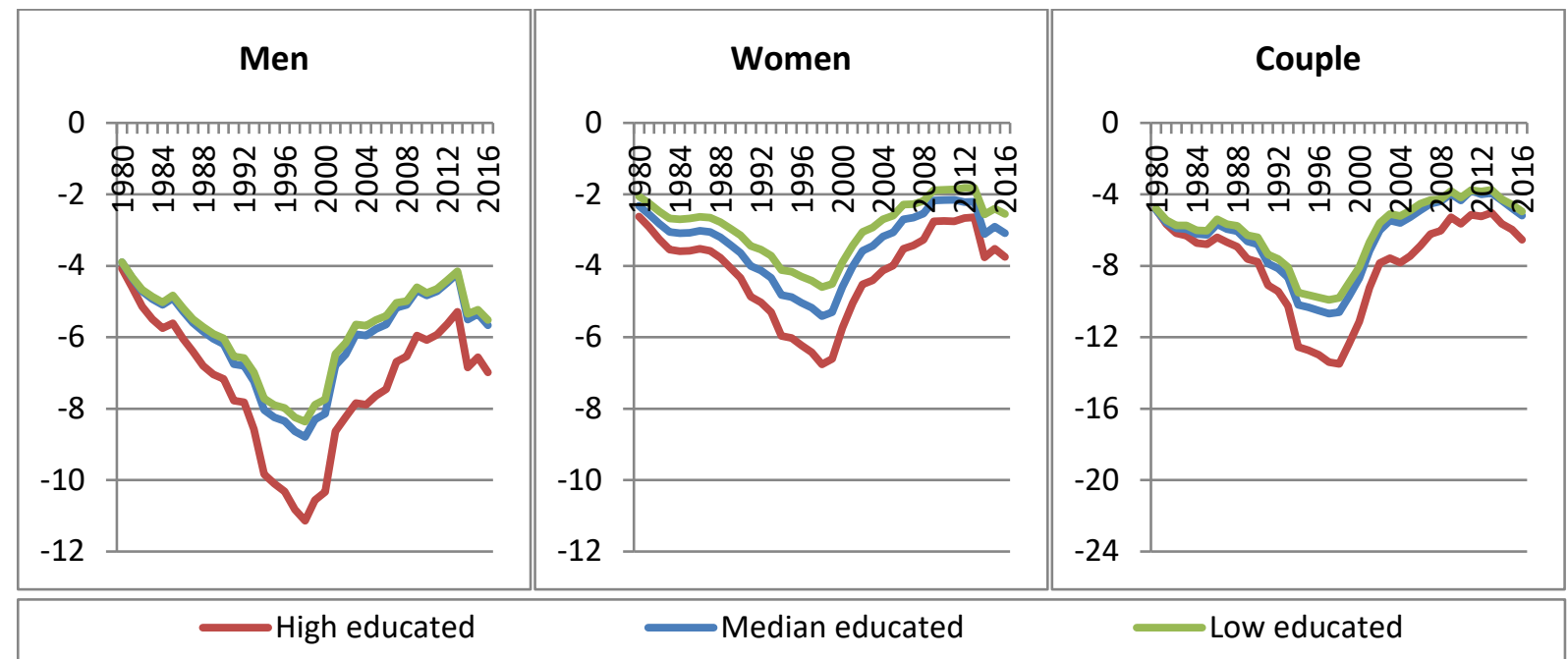

Source: Authors' own calculations.

\subsection{Common macro environment: Implicit taxes on working longer}

Implicit taxes are defined as the accrual as shown in the preceding subsection divided by the most recent earnings. This subsection analyzes the median educated single men's case and proceeds with the median educated single women's and the median educated couple's cases. Subsection 5.4 discusses the differences between the three skill groups.

Figure 20 and Figure 21 display the median educated men's implicit taxes in the common macro environment. Figure 20 shows for all considered claiming ages the development of the implicit taxes over time. For readability reasons we divide Figure 20 into three subgraphs. The first one shows the implicit taxes for the early labor market exit ages between 55 and 59; the second graph contains the implicit taxes of the main early retirement window between 60 and 64; and the third graph depicts the implicit taxes at and after the statutory eligibility age. Figure 21 depicts the same data for a selection of four planning years $\left(1985,1995,2005\right.$, and 2015) by age. ${ }^{11}$

We observe for almost each case positive implicit tax, hence incentives to leave the labor market immediately. A general exception is the age 65 and 66 with negative implicit taxes until 1992. The implicit taxes at age 55 to 57 lie over the whole observation time constantly around 19 percent. Hence, there exists already at those early ages an incentive to leave the labor market immediately. Until 1985 the implicit tax at the age of 58 had a similar level. However, this implicit tax rose by more than 5 percent points when the extension of the duration period of unemployment benefits in 1985 (see Table 5) enabled individuals to build a bridge to retirement from this age on. Moreover, the implicit tax grew further in the early 1990s due to the general increase of unemployment. This process ended in 1996 when the first cohort who had to

\footnotetext{
${ }^{11}$ Note that in both cases the same results are depicted. Only the considered dimension varies.
} 
accept actuarial deductions for claiming an old-age pension because of unemployment at the age of 60 reached the age of $58 .{ }^{12}$ In fact, the implicit tax even decreased as individuals can now avoid annual actuarial deductions of 3.6 percent by postponing claiming unemployment benefits and thereafter a pension to the following year. The overall deduction effect increased thereby over the introduction period of the actuarial deductions since the total deduction for claiming a pension at the age of 60 increased stepwise from 3.6 percent to 18 percent (5 time 3.6 percent) (see Table 6). Since all actuarial deductions are introduced in an analogous pattern, we observe a similar qualitative development for other ages. In the further process the implicit tax of age 58 went back to the level of the implicit taxes at ages 55 to 57 . The main reason for this further decline is the abolishment of the old-age pension pathway due to unemployment (see Table 1). The pattern is similar for age 59. However, the implicit tax was from the beginning larger than for younger claiming ages since one year of unemployment benefits was sufficient to build a bridge to retirement. Moreover, the drop of the implicit taxes appeared two year later in 1998. This time lag results from the fact that the first cohort who had to accept actuarial deductions for claiming an old-age pension due to unemployment at the age 61 reached the age of 59 two years later. In general, we observe the same two-year time lag for all subsequent ages and cases (introduction of actuarial adjustment for other pension pathways like the old-age pension for women).

Between 1980 and 2000 the implicit taxes during the early retirement window (ages 60 to 65) were larger than the implicit taxes of the preceding claiming ages. Implicit taxes are around 35 percent for the claiming ages 60 to 62 and around 47 percent for the claiming ages 63 and 64. These rather large implicit taxes declined with the introduction of the actuarial deductions between 2000 and 2004 . For the ages 60 to 62, the implicit taxes dropped by more than 25 percentage points to the level of the implicit taxes of the age group 55 to 59. This reduction occurs in two steps. The first drop results from the introduction of the actuarial deduction for the old-age pension for disabled the second one is due to the introduction of the actuarial deduction for the old-age pension due to unemployment. For the ages 63 and 64, the implicit taxes dropped by 11 percentage points to 40 percent. After the introduction of the actuarial adjustments we observe a further decrease of the implicit taxes which can be explained by the reduction of the replacement rates caused by the introduction of the sustainability factor. Contrary to this general trend the implicit taxes of the claiming age 63 and 64 increased in 2014. The reason is the introduction of a new early retirement pathway called "pension with 63" which enabled individuals to claim a pension at age 63 and 64 without deductions (see Section 3). In fact, the increase of the implicit taxes match with the now abolished effect of the actuarial deductions.

As already mentioned the implicit taxes of the ages 65 and 66 were negative until 1992. Hence, until 1992 there was an incentive to postpone the pension claiming beyond the age 65 and 66. On the other side, the implicit tax rates of ages 67 to 69 were extreme large with values above 60 percent. This apparent

\footnotetext{
${ }^{12}$ Note that the 58 year old individuals draw unemployment benefits for the age 58 and 59 and claim afterwards their pension at the age of 60 .
} 
contradiction results from the actuarial supplements for postponing the pension claiming beyond the statutory eligibility age as they were organized until 1992. While actuarial supplements of 7.2 percent for postponing the pension claiming to the age of 66 and 14.4 percent for postponing the pension claiming to the age of 67 prevented positive implicit taxes (actuarial fair adjustments), there were no actuarial supplements for postponing the pension claiming beyond age 67. As the general actuarial supplements of 6 percent were introduced in 1992 the implicit taxes dropped consequently considerable for the claiming ages 67 to 69. All in all, we observe a reduction of more than 30 percentage points. The reduction was, thereby, larger for later claiming ages. However, since the actuarial supplements for postponing the pension claiming at the age of 65 and 66 were reduced at the same time the implicit taxes of those claiming ages started to increase by approximately 20 percentage points which corresponds to the reduction of the former actuarial supplements. Similar to the claiming ages 60 to 64, the implicit taxes of the claiming ages 65 to 69 started to decrease in 2004 due to the introduction of the sustainability factor. For the most claiming ages this decrease continued until today. An exception represents the claiming age 65 for which the implicit tax started to increase in 2012. The explanation for this opposite development lies in the increase of the statutory eligibility age from 65 to 67 . The incentive to leave the labor market increases due to the fact that an individual does not anymore receive higher actuarial supplements for postponing the pension claiming beyond the statutory eligibility age but prevents only the smaller actuarial deduction for claiming a pension before his statutory eligibility age. Once the transition to the higher statutory eligibility age is completed, the implicit tax of the claiming age 65 should have risen to a similar level as of the implicit taxes of the claiming ages 63 and 64 . 
Figure 20: Median educated men's implicit taxes over time by age.

a) Implicit taxes for ages 55 to 59

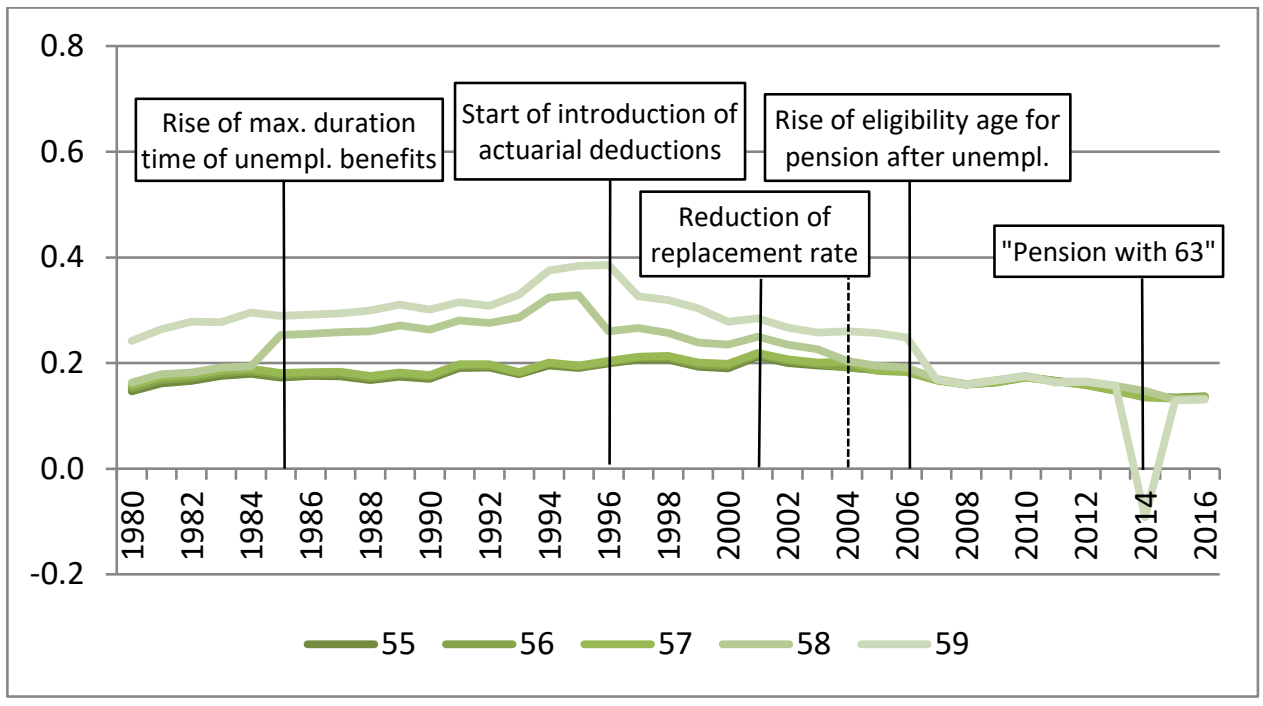

b) Implicit taxes for ages 60 to64

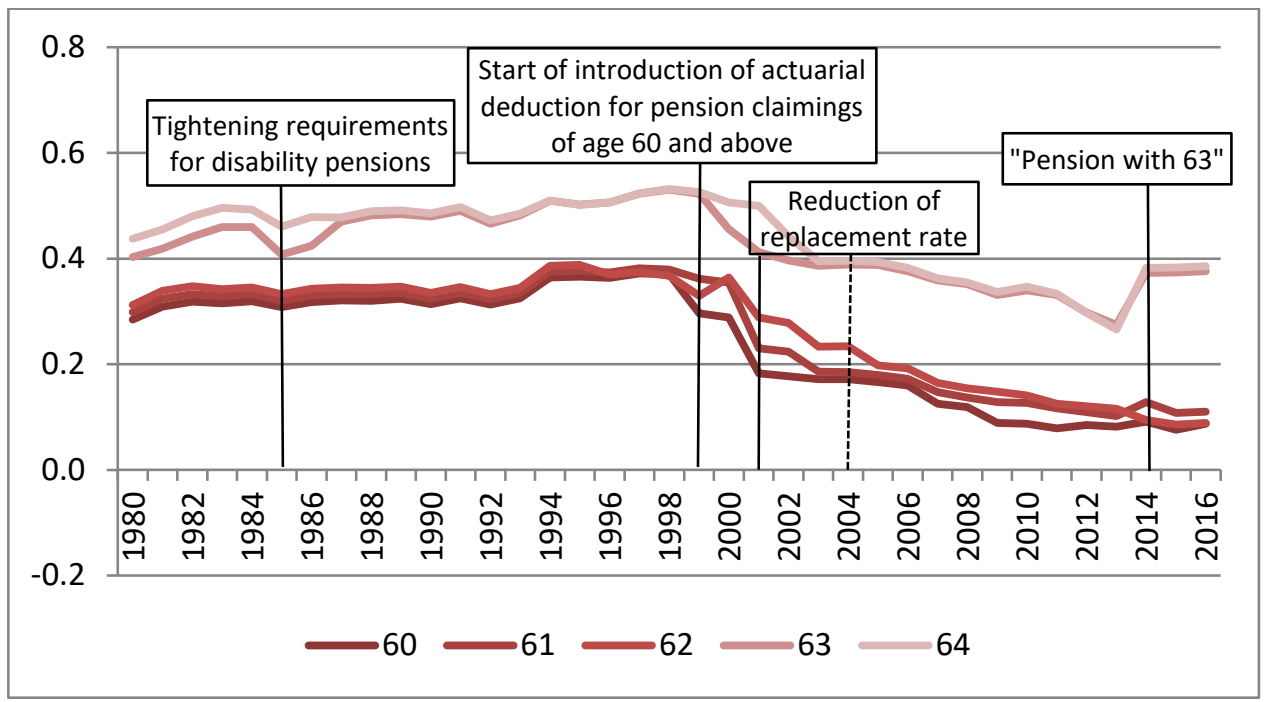

c) Implicit taxes for ages 65 to 69

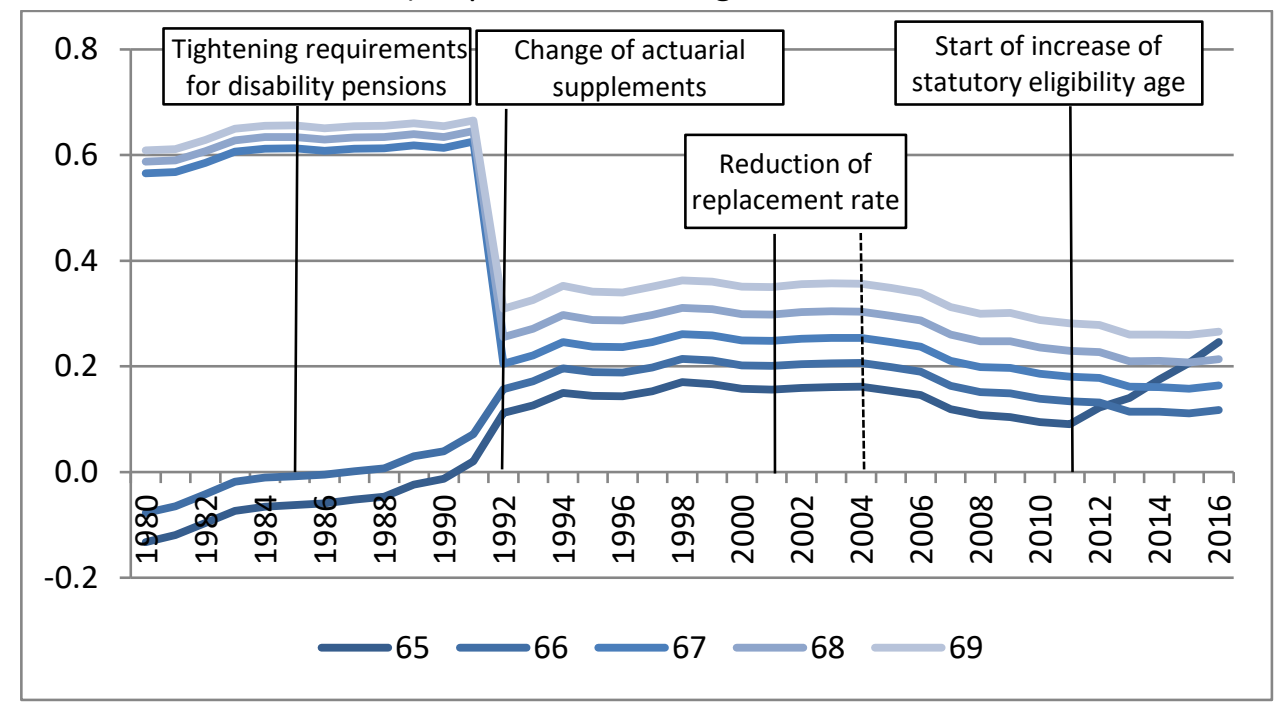

Source: Authors' own calculations. 
Figure 21: Median educated men's implicit taxes by age.

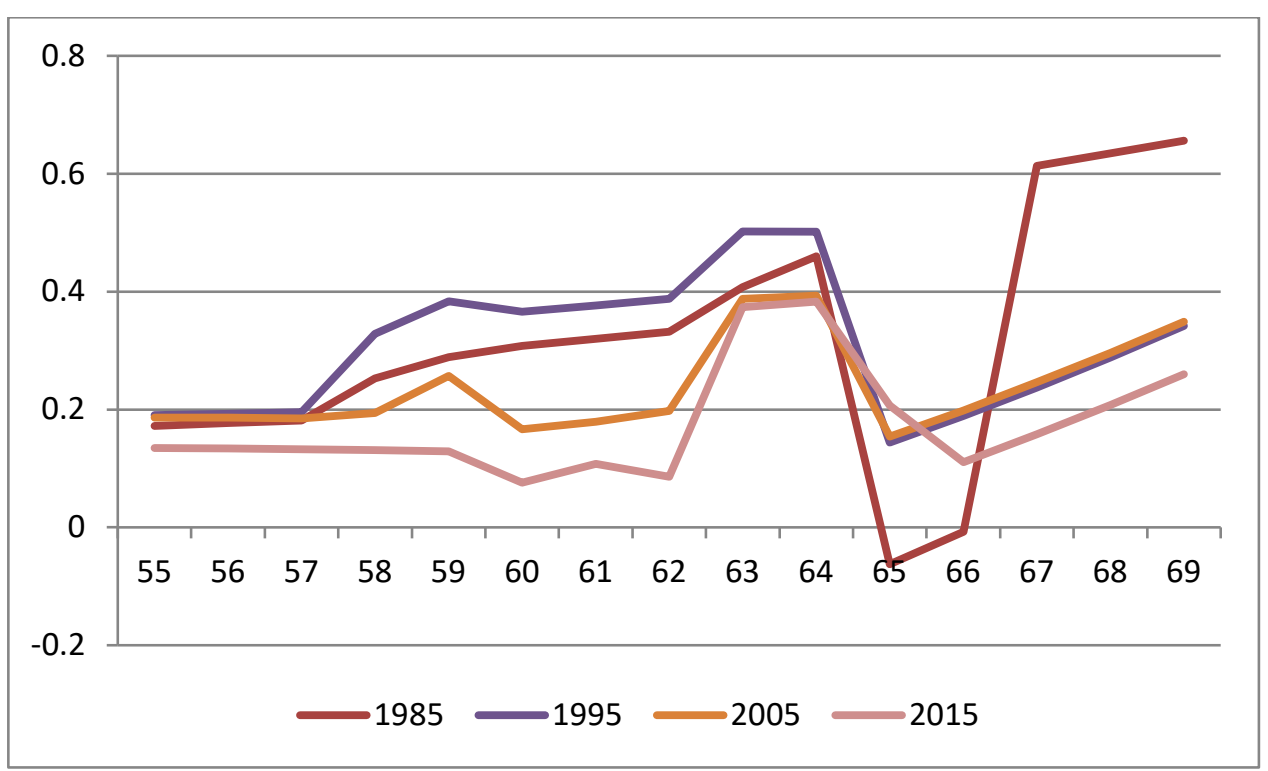

Source: Authors' own calculations.

The women's implicit taxes developed in a similar manner as the men's implicit taxes (see Figure 22 and Figure 23). However, their implicit taxes are smaller due to their higher life expectancy, lower tax rates and smaller replacement rates. Moreover, there are some additional differences to the men's case. First, we observe a smaller differences between the implicit taxes of the claiming age 58 and 59 and the implicit taxes of the claiming ages 55 to 57 . The main reason is that the distribution of the women's pension claims includes only a small fraction of old-age pensions due to unemployment. Hence the pathway via unemployment is less relevant in the women's case as compared to the men's case. Second, the implicit taxes at ages 60 to 62 are similarly large as the implicit taxes at ages 63 and 64 . This can be explained with the old-age pension for women which enabled more or less all women to claim a pension at age 60 without eligibility requirements such as unemployment or disability. As shown in Figure 9 most women used this retirement pathway. As a consequence, the introduction of the actuarial deductions for the old-age pension for women had a very large effect on the implicit tax. 
Figure 22: Median educated women's implicit taxes over time by age.
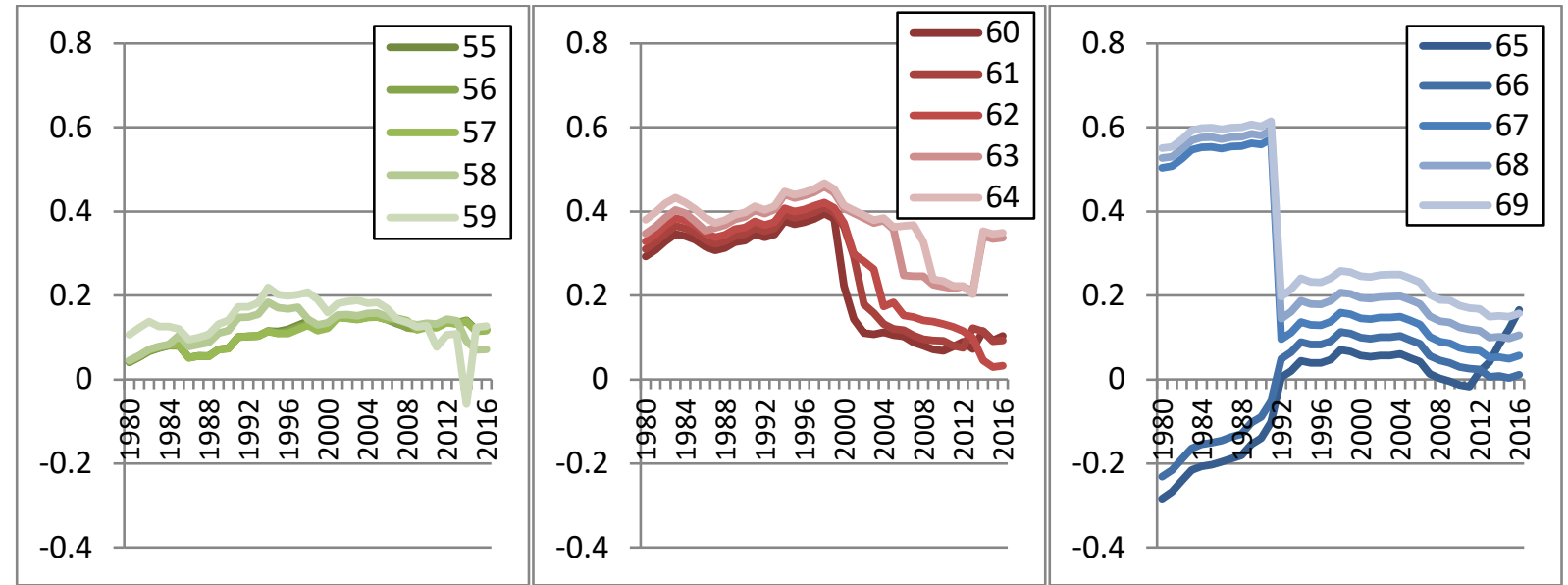

Source: Authors' own calculations.

Figure 23: Median educated women's implicit taxes by age.

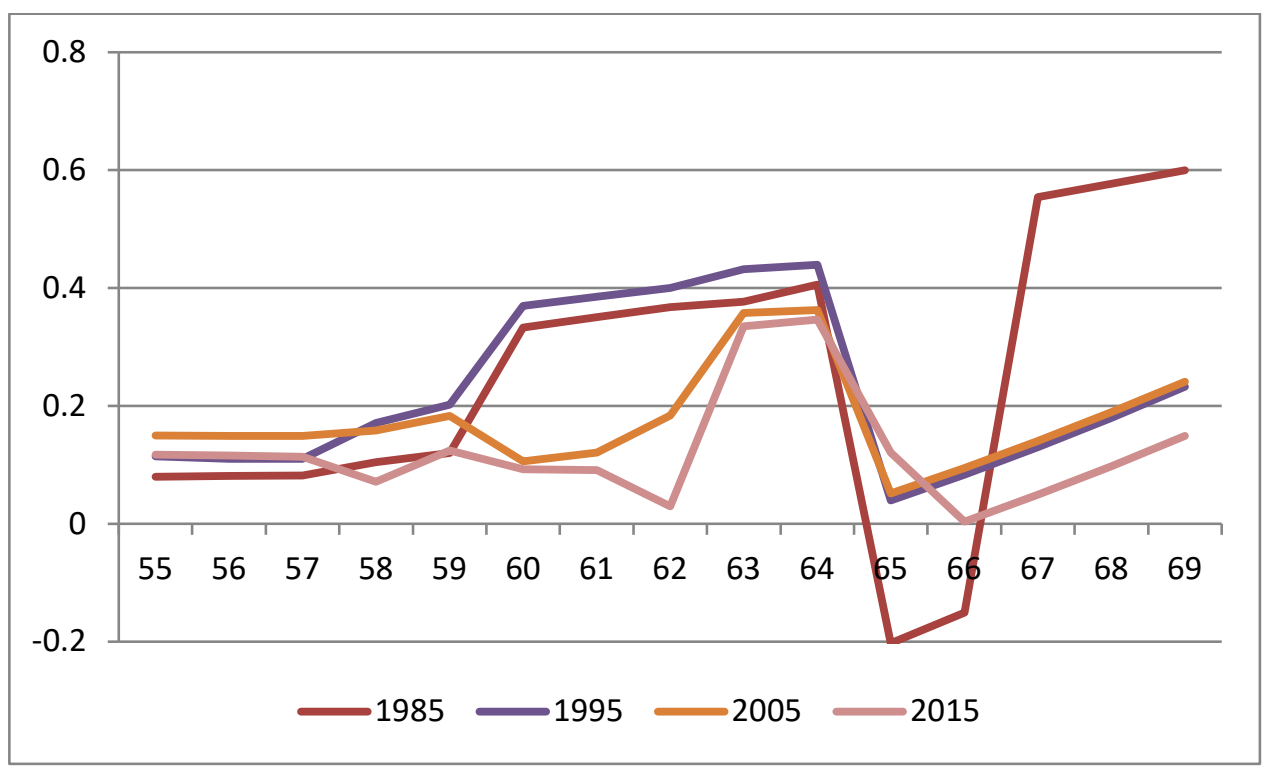

Source: Authors' own calculations.

Finally, Figure 24 and Figure 25 depict implicit taxes for median educated couples. The claiming ages refer to the age of the husband; women are assumed to be three years younger. The general development is similar to the single household case. However, there are some differences due to the age differences of the spouses. For example, the implicit tax at the husband's claiming age 69 is smaller than in the single household case. The reason is that the wife is only 66 at this time. Hence, if the couple postpones claiming by one year, the women could gain the actuarial supplement for postponing the pension claiming beyond the statutory eligibility age. This had a large effect especially before 1992. Similar observations can be made for other claiming ages. 
Figure 24: Median educated couple's implicit taxes over time.
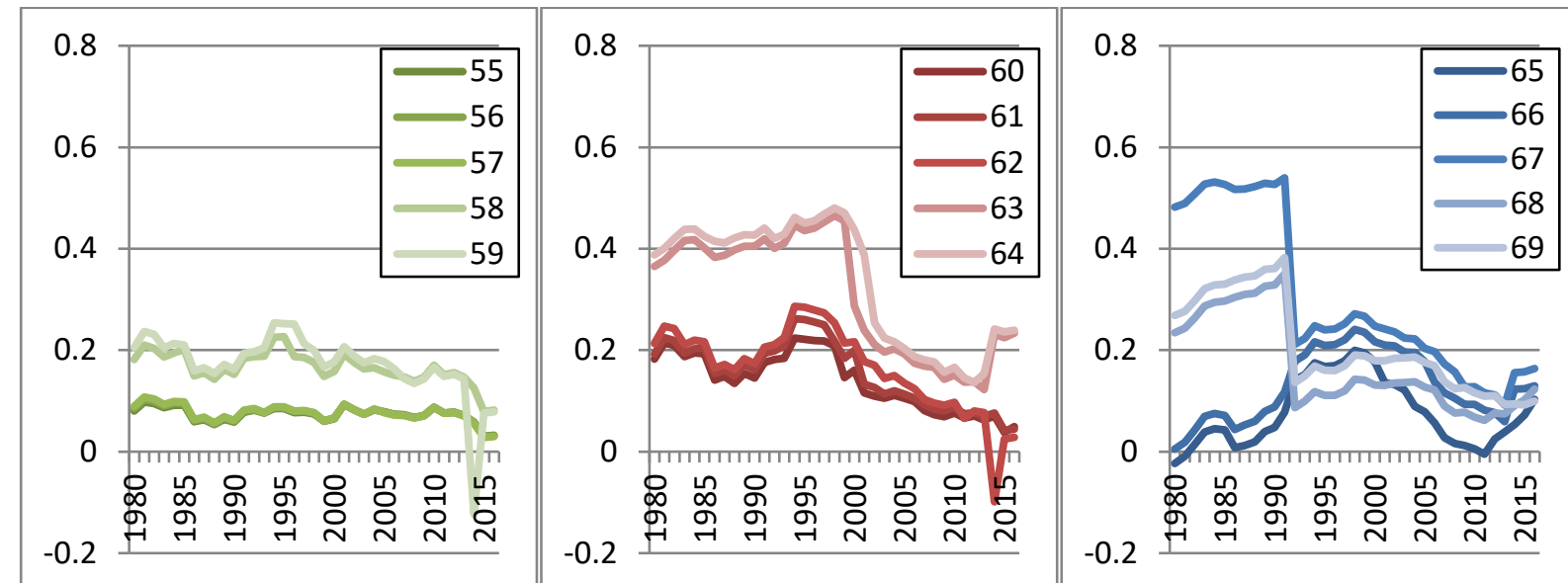

Source: Authors' own calculations.

Figure 25: Median educated couple's implicit taxes by age.

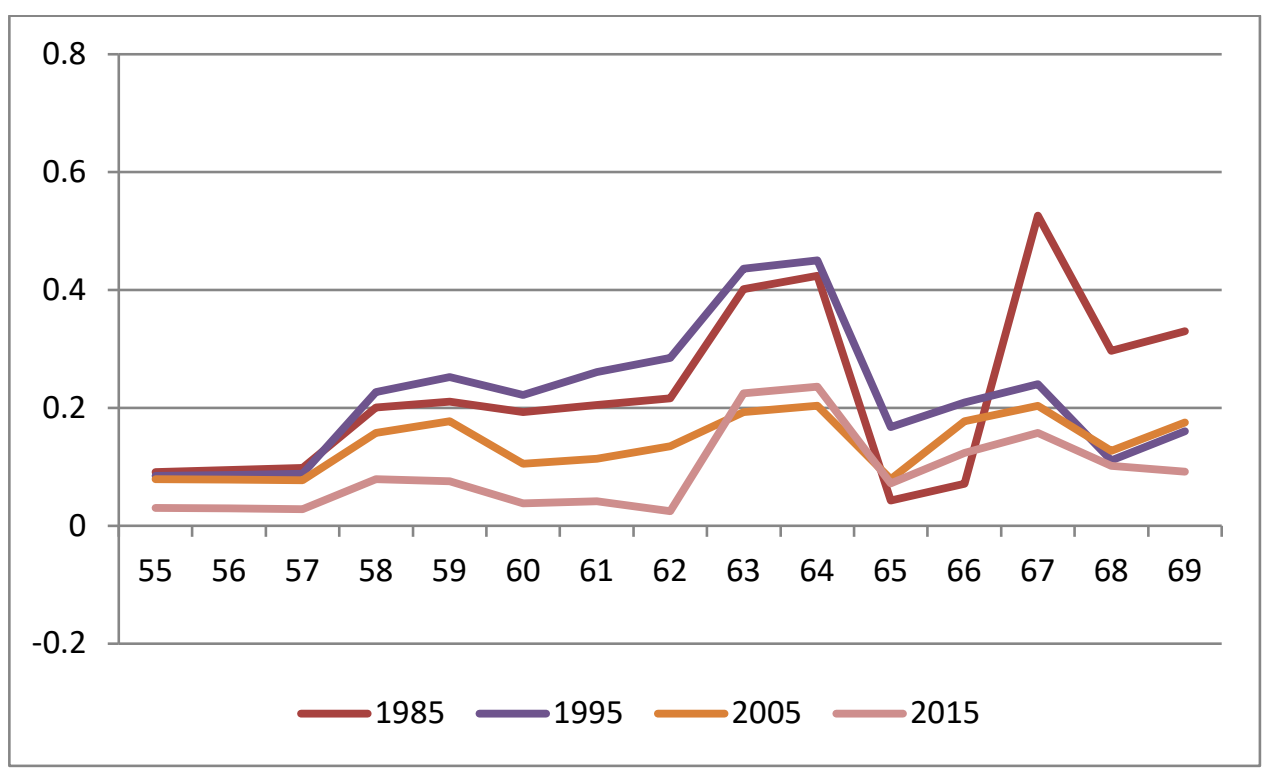

Source: Authors' own calculations.

\subsection{Implicit taxes on working longer by education/skill}

So far, we have studied the implicit taxes for median educated individuals. This subsection looks at the differences across the three skill groups. We consider the average implicit taxes of the age groups from 60 to 64 only. Our findings are similar for other age groups. Figure 26 depicts the implicit taxes over time separately for single men, single women and couple by skill group. We can make two observations. First, the implicit taxes decrease with education. The gap is especially large between high and median educated individuals. Second, we observe that the gap between the implicit taxes decreases over time. This results from the introduction of the actuarial deductions since they have a greater effect on individuals with a lower life expectancy. Hence, the implicit taxes for low and median educated individuals decrease stronger due to the introduction of the actuarial deductions than the implicit taxes for the high educated. 
More generally, the difference among the skill groups has three reasons: first, differences in the assumed life expectancy, second, different tax rates on the last labor income, and third, differences in the replacement rates. A higher life expectancy reduces the implicit tax since the additional pension claims for a postponement of claiming are received over a longer time horizon and offset a larger part of the pension benefits and contributions lost due to the additional working year. The relevance of the income tax rates and the replacement rates results from the division of the strictly gross income related additional benefits and contributions by the last net income.

Figure 26: Implicit taxes aggregated over age 60 to 64 by education group.

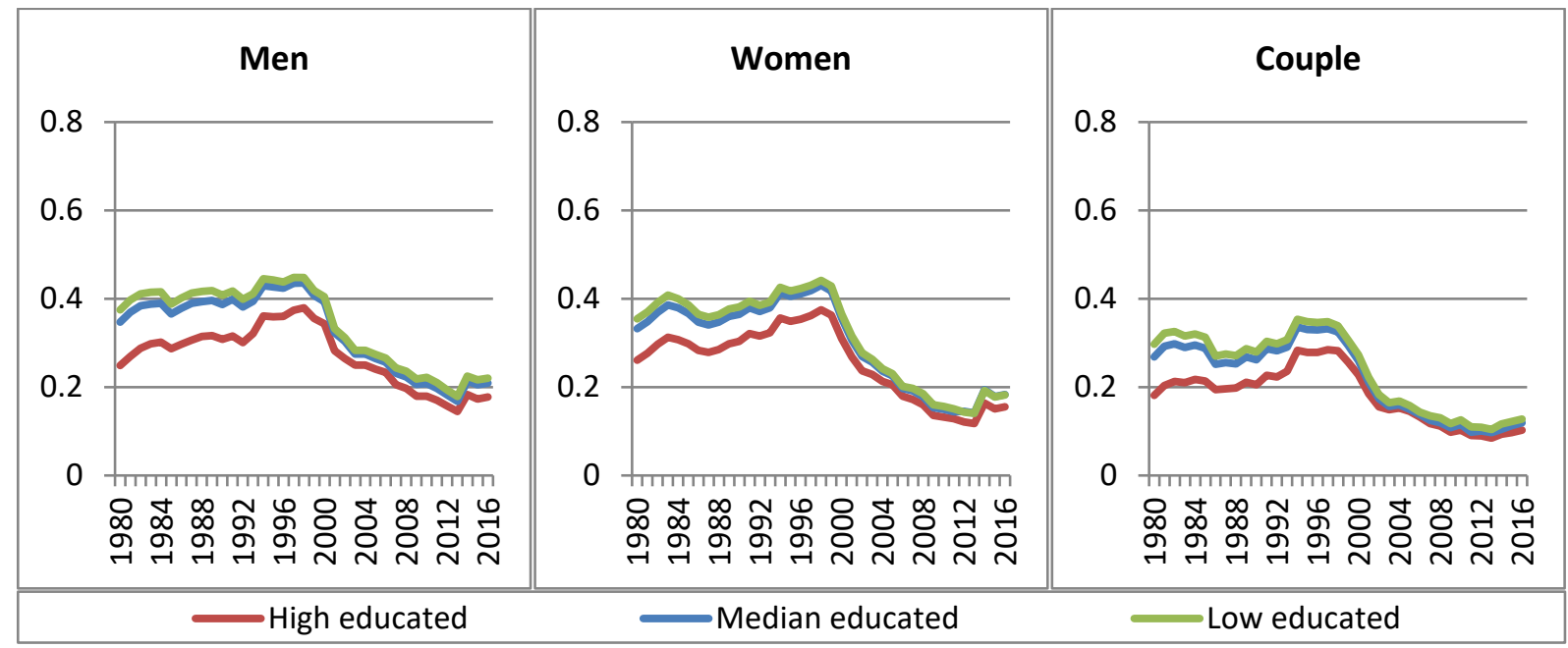

Source: Authors' own calculations.

\subsection{German macro environment: the influence of changes in the taxation, cohort-specific income profiles and survival probabilities}

We now switch from the common macro environment to the German macro environment. We discuss in which way taxation, cohort-specific income profiles and survival probabilities influence the implicit taxes. We start with taxation, then proceed with analyzing the income profiles and close with the survival probabilities.

Figure 27 depicts the average implicit taxes of single men, single women and couple at the claiming ages 60 to 64 for different taxations of the gross pension and labor income. All figures are aggregated over the three education groups. We consider three cases: first, the common taxation used in the common macro environment; second, the German taxation according to our tax calculator but without the introduction of the deferred taxation and finally German taxation with deferred taxation. The income profiles and survival probabilities remain as before and are taken from the common macro environment. ${ }^{13}$

\footnotetext{
${ }^{13}$ Note that the last case corresponds to the case for which we had presented the replacement rates and social security wealth shown in subsection 5.1.
} 
Until 2000, we observe for each case smaller implicit taxes under the common taxation than under the timespecific German taxation. The gap is larger for men than for women. It results from the fact that under the common taxation not only the labor income is taxed but also public pension benefits. At the end of the 1990s, the gap becomes smaller and since 2000 the implicit taxes are larger under the common taxation than under the German time-specific taxation (at least if we do not consider the deferred taxation). This reversal is due to the introduction of the actuarial deductions which reduce the gain of claiming a pension immediately.

We have already shown that the deferred taxation has had a large influence on the determinants of the implicit taxes such as the replacement rate. Consequently, we also see a large reaction of the implicit taxes to the introduction of the deferred taxation, see Figure 27. The deferred taxation led to an increase of the implicit taxes for single men and couples. This effect is larger for higher claiming ages and conceals most of the effects that we have observed in the previous section, e.g. the effect of the "pension with 63" or the effect due to the increase of the statutory eligibility age. That we do not observe an effect on the women's implicit taxes results from their rather small pension benefits and the large tax allowances which were granted at the beginning of the introduction of the deferred taxation. With the decrease of these tax allowances the women's implicit taxes will be similarly influenced by the deferred taxation.

Figure 27: Average implicit taxes (of ages 60 to 64) for common and German taxation.

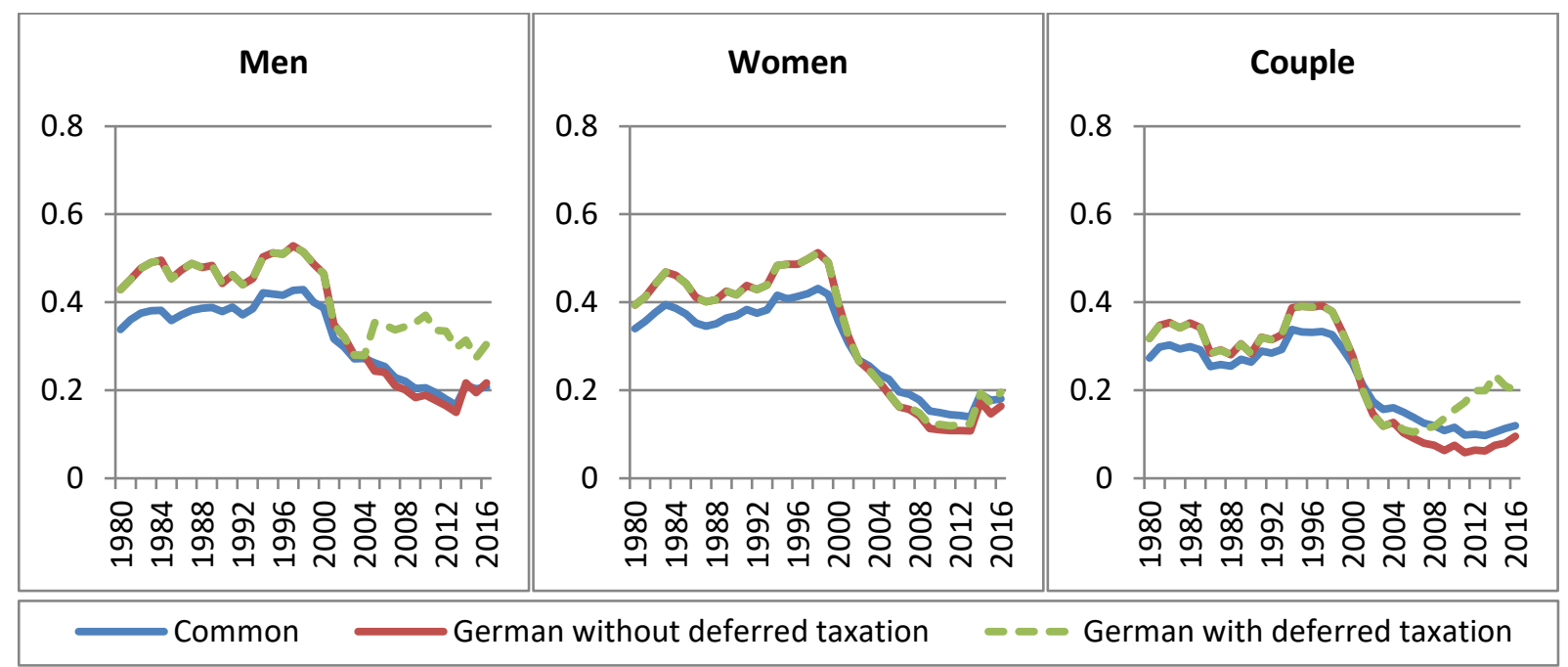

Source: Authors' own calculations.

Figure 28 depicts implicit taxes for different income profiles and survival probabilities. The panel dubbed "common" depicts the implicit taxes for the common macro environment but with German taxation. The other two lines replace consecutively the common earnings profiles by German cohort-specific earnings profiles and the common survival probabilities by the German cohort-specific survival rates.

We do not observe relevant changes in the implicit taxes if we change the underlying earnings profiles. A somewhat larger effect can be observed when we change the underlying survival probabilities. Implicit 
taxes of earlier ages increase due to much lower life expectancies of older cohorts. However, also this effect is rather small.

Figure 28: Average implicit taxes (of ages 60 to 64) for common and German cohort-specific income profiles and survival probabilities.

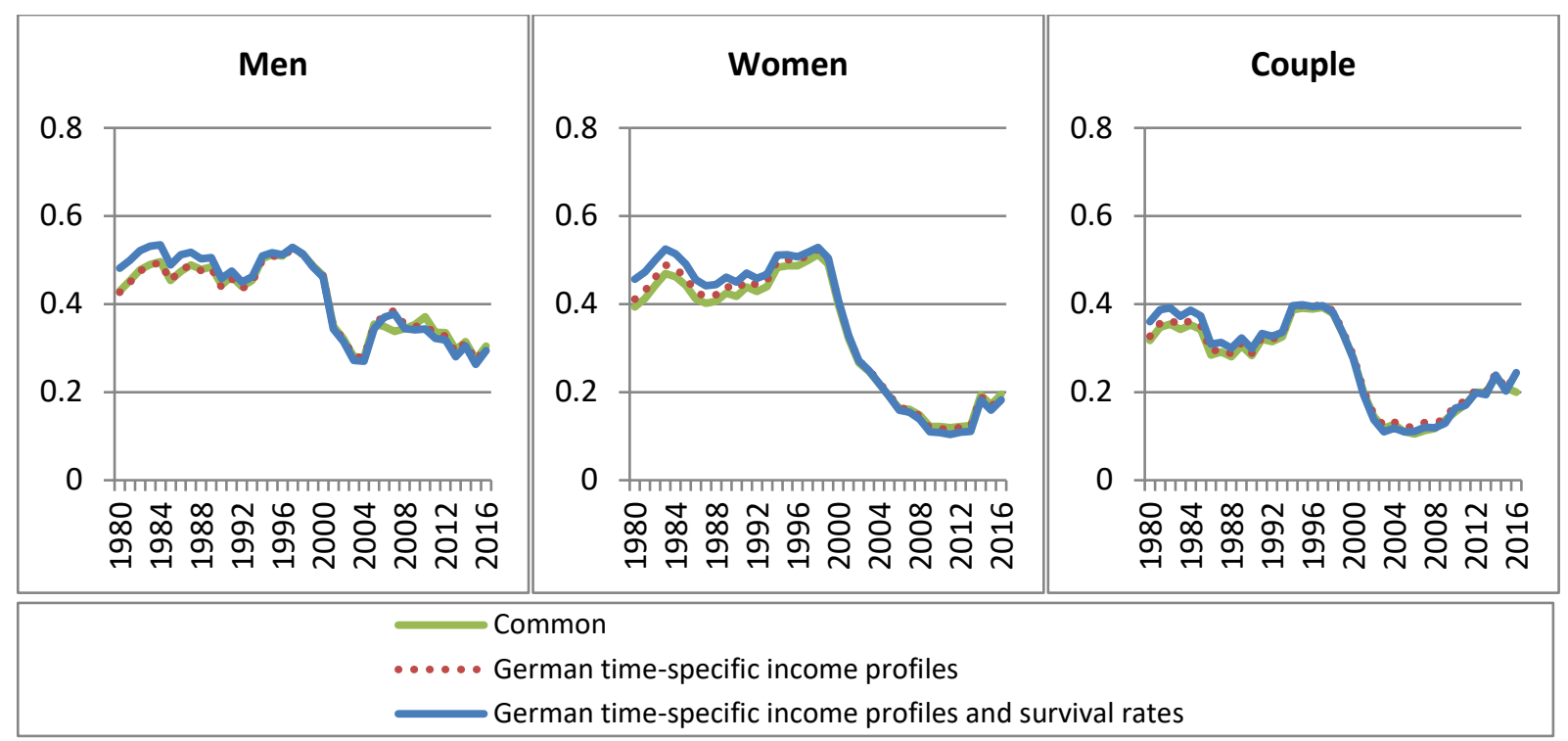

Source: Authors' own calculations.

\subsection{Relation between implicit taxes and employment rates}

This subsection graphically links the development of the implicit tax with the development of the employment rate. ${ }^{14}$ We plot the average employment rates of older workers by age groups of 55-59, 60-64, 65-69 and 55-69 (see Figure 1) against the average implicit taxes of the same age groups (for age group 6064 see Figure 28). The result is shown in Figure 29. We first discuss the differences among age groups. For both men and women we see that younger age groups have large employment rates and smaller implicit taxes while the older age groups have smaller employment rates and higher implicit taxes. Hence, we observe a negative correlation between employment rates and implicit taxes.

Within each age group, the picture is less clear. This is especially the case for the age group 55 to 59 since their implicit taxes did not change much for both single men and single women. For the age group 65 to 69 we observe for single men that the employment rate increases after the implicit taxes decreased. However, there seems to be a time lag between both events. In the women's case the increase of the employment rate for the oldest age group is rather small. Moreover, the implicit taxes increased again after 2000 which yields a positive correlation. However, the increase of the implicit taxes results from the deferred taxation which may not yet be anticipated in the pension plans of older individuals. The picture is clearer for the age group of the 60 to 64 year old individuals. For instance, the men's picture resembles a U-shape. First, the employment rate decreased while the implicit tax remains at a high level of around 50 percent. The implicit

\footnotetext{
${ }^{14}$ In the women's case we will use the corrected employment rates.
} 
tax then decreased very rapidly. At the same time the employment rate starts to increase. This growth process accelerates and even continues after the implicit tax reached a new steady state around 25 percent. The plot is quite similar in the women's case, although the initial decrease in the employment rate is missing. Another relevant difference is that the major part of the fast drop in the implicit tax happened in the women's case in one year while this process needed three years in the men's case. On the other hand, the decrease of the implicit tax lasted longer in the women's case thus that the implicit tax decreased from 45 percent to a value below 10 percent. However, the increase of the employment rate again starts also in this case together with the decrease of the implicit tax. All observations taken together, we observe a negative correlation between employment rates and implicit taxes. The picture for the age group 55 to 69 is similar to the age group 60 to 64 . However, the quantitative changes are smaller.

\section{Figure 29: Employment rate versus implicit tax.}

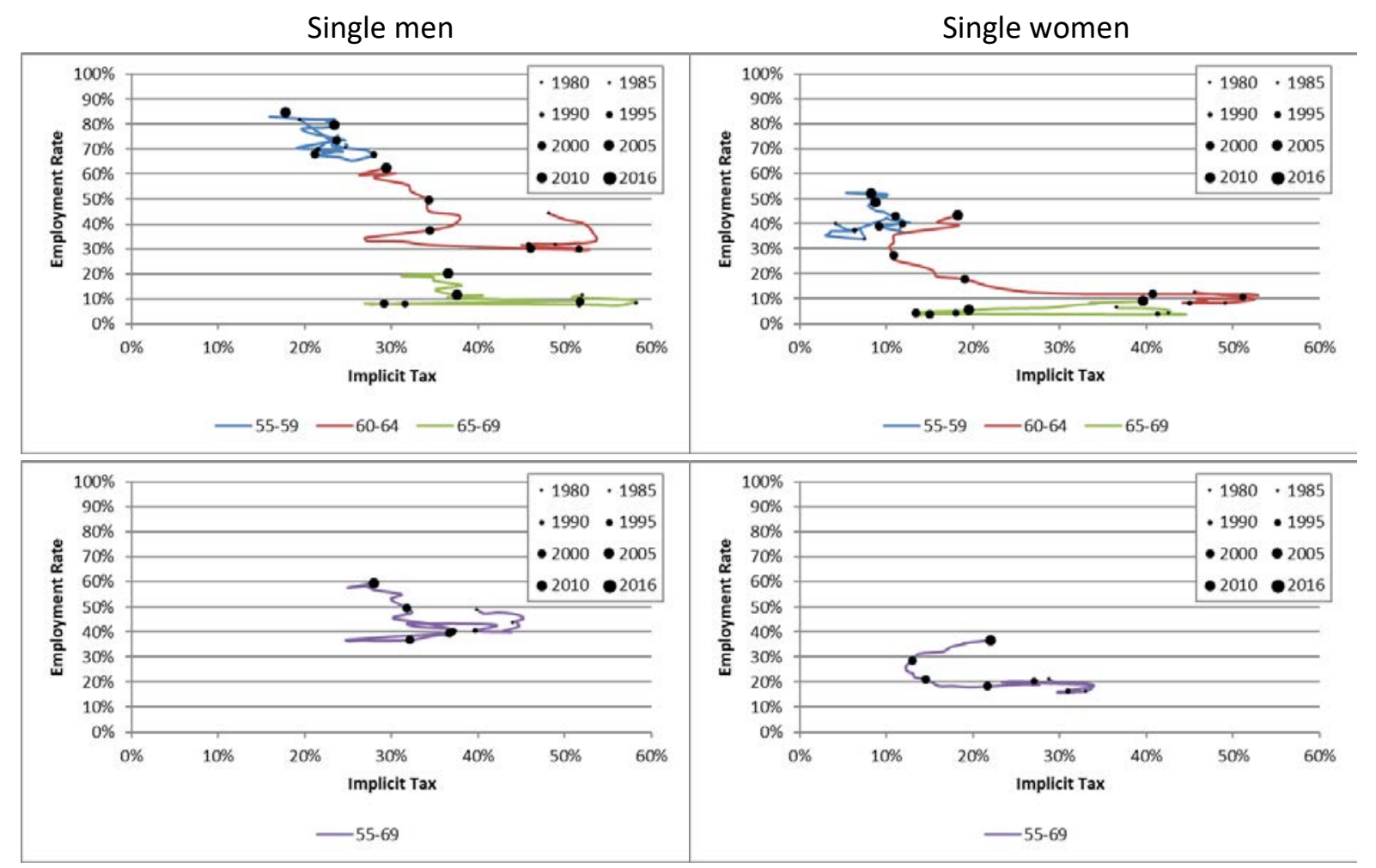

Source: Authors' own calculations.

\subsection{Relation between implicit taxes and pension claiming ages}

Finally, we compare the development of the implicit tax with the distribution of pension claiming ages during the retirement window from 60 to 65 . As mentioned before, we will consider hereby an alternative weighting procedure such that the implicit taxes may differ slightly from those just presented. However, the general development and the differences between the skill and age groups do not change.

For the pension claiming behavior at a certain age $a$ two implicit taxes are relevant. First, there is the implicit tax of the previous age (a-1). If it becomes negative it would indicate an incentive to postpone the 
pension claiming by one year. Hence, one year later the number of individuals claiming their pension at age $a$ should increase. Actually, even only a decrease of the implicit tax at age $a-1$ could lead to an increase of the pension claiming as the monetary incentive to claim their pension immediately declines. The other relevant implicit tax is the implicit tax of the current age. If the implicit tax becomes smaller or even negative, postponing the pension entry becomes less disadvantageous and can lead to a smaller share of pension claims at this age. Of course, there are other factors, like the abolishment of early retirement pathways, which may counteract to the implicit tax’s effect on the pension claiming behavior.

Figure 30 shows in separate graphs for each pension claiming age between 60 and 65 the development of its share on all pension claims of the respective year (left side men, right side women). Moreover, each graph includes the development of the implicit tax at the observed pension claiming age and the previous year. In general, our observations are in line with the previous discussions. We start with the pension claiming age 60. For both men and women, the implicit tax of the previous age (59) does not change in a relevant way. Hence, there are no changes in the incentive to leave the labor market at the age 59. On the other hand, there are quite large changes in the implicit tax at the age of 60 as we have seen in the previous subsection. In line with our previous argumentation these changes coincide with increases and decreases in the pension claims (higher (lower) implicit tax lead to more (fewer) pension claims). The decrease in pension claims after the introduction of the actuarial deduction and their impact on the implicit taxes is remarkable. Only the decrease in the pension claims after 2012 cannot be linked to a change in the implicit tax. In fact, the reason for the drop is the abolishment of the old-age pension for women and due to unemployment. Apparently, the abolishment of those pension pathways did not affect the implicit taxes of the age 60 since both the social security wealth with an immediate and with a postponed labor market exit are affected equally. For the pension claiming ages 61 and 62 the opposite happens. First, pension claims increase after the implicit tax of the previous age declined. Afterwards the pension claims decrease several years later together with the decline in the implicit tax of the considered age. Hence, the pension claiming rose only temporally together with the shift of the pension claiming from the age 60 to age 63 or 65 .

For the pension claiming age 63 we have to differ between the men's and the women's case. In the men's case the pension claims are rather constant until 2010. Smaller changes are again in line with the respective development in the implicit taxes. However, after 2009 the share of individuals who claim their pension at 63 increases rapidly. The main reason is that with 2009 the age 63 became for not disabled individuals the earliest eligibility age for an old-age pension. Moreover, the implicit tax still indicates a strong incentive to claim the pension immediately.

For women most of the observations are the same. However, due to the actuarial deductions and their higher life expectancy there remains no monetary incentives to leave the labor market before the age 63 since 2003. In fact the age of 63 is the first age with positive implicit taxes. In line with our argument, pension claims at this age increase since 2000, i.e., as soon as the actuarial deductions were introduced. The most recent and very strong increase in pension claims can be explained with the abolishment of the old-age 
pension for women. The pension claims at age 64 increase one year after the implicit tax of the previous age declined.

For the former statutory eligibility age of 65 we again need to differentiate between men and women. In the men's case we observe again the assumed development. Hence, the pension claims increase after the implicit tax of the age 64 declines. At the same time the implicit tax of the age 65 are positive and even increased such that there is no incentive to further postpone pension claiming. For the women we observe an up and down in the frequency of pension claiming which corresponds to the observe development of the implicit tax at age 64. However, since the implicit tax at age 65 is approximately zero, there is no incentive to retire immediately which contradicts the observed high share of pension claims at age 65 . The high share of initial pension claims at the historical statutory eligibility age 65 which is found in so many studies of retirement may be due more to habit formation than to current monetary incentives. 
Figure 30: Development of single person's implicit tax and pension claiming at different ages.

Men
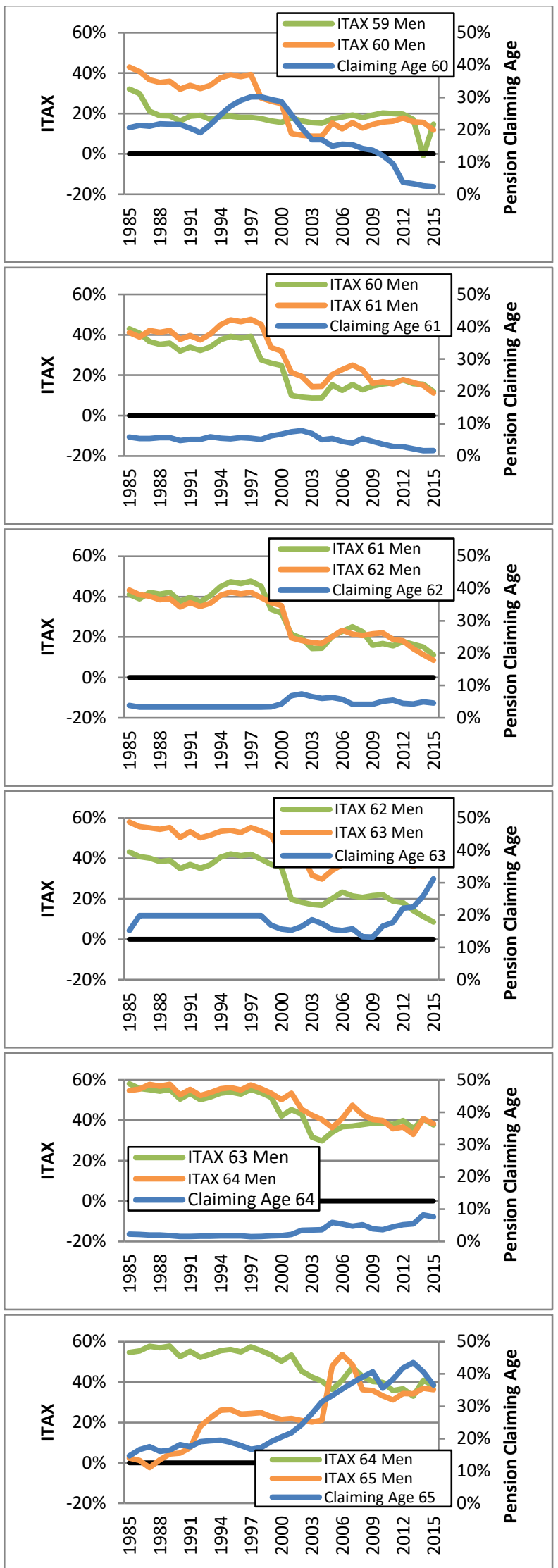

Women
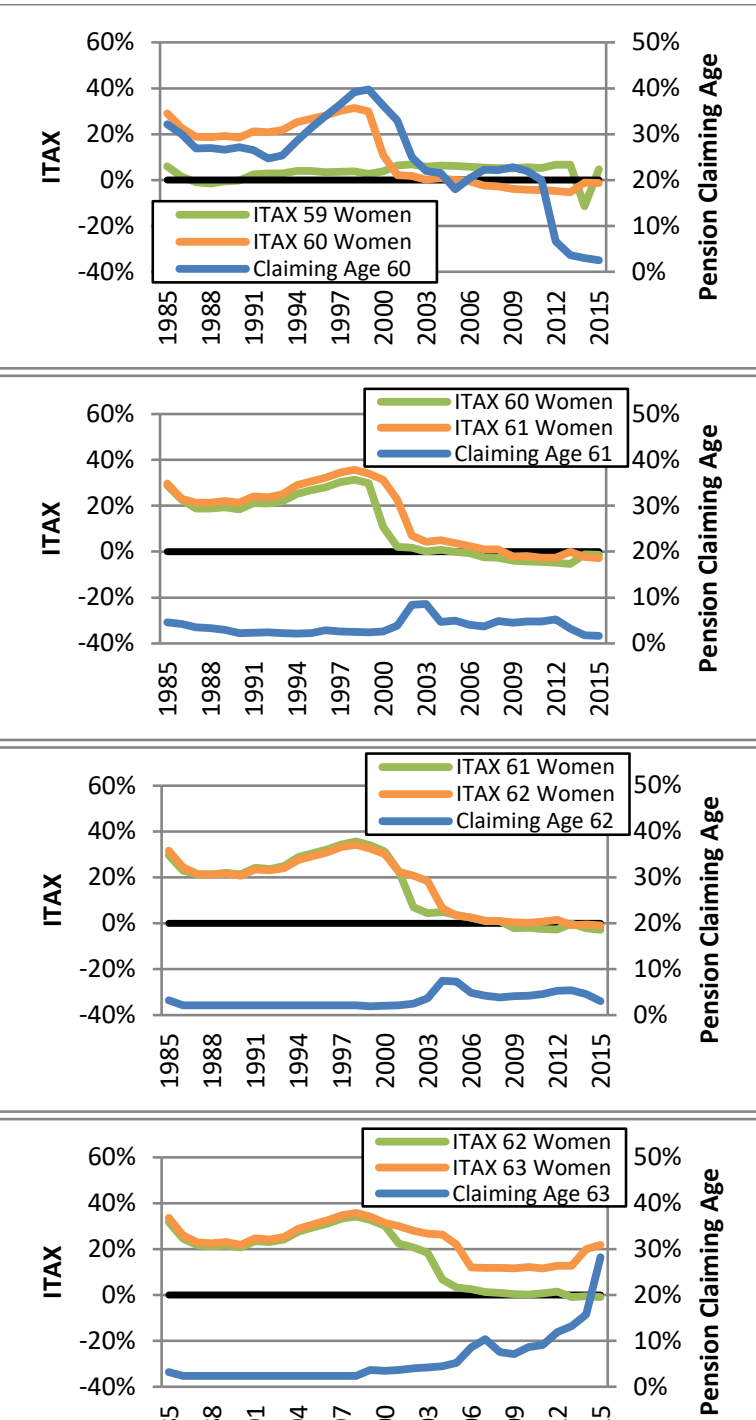

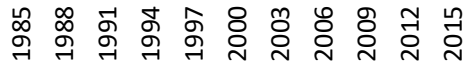

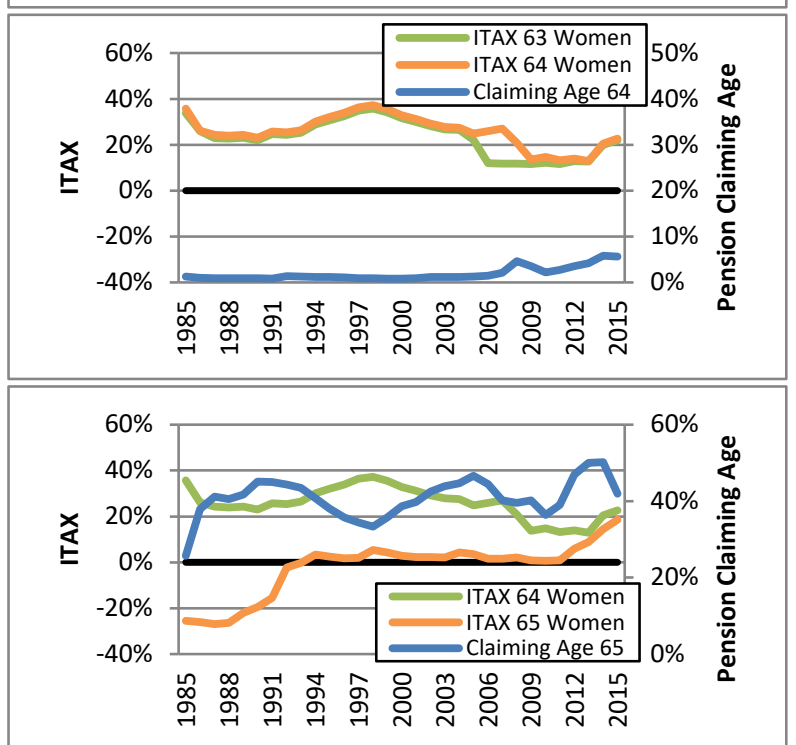

Source: Authors' own calculations. 


\section{Conclusions}

Employment of older individuals in Germany has experienced a remarkable reversal around the late 1990s. After a long declining trend that began in the early 1970s, the employment rate for older men has strongly increased again. This increase has lasted until today. In contrast, employment of older women in Germany has experienced a less pronounced U-shaped pattern in particular because employment of younger women has steadily increased since the 1970s. This paper has linked these trends to changes in public pension policies. The key instrument of our analysis was the concept of “implicit taxes on working longer" which represents the monetary incentives that individual face in their labor supply and pension claiming decisions. In this paper, we compute implicit taxes for a set of synthetic individuals differing by household demographics and education/skill, once based on a common macro environment across all 12 countries in this project and once based on German age-earnings profiles, payroll taxes and survival probabilities.

We find that for both men and women the increase in the employment rate coincides with a reduction in the early retirement incentive expressed by the implicit taxes on working longer (Figure 29). The reduction of incentives mainly stems from the introduction of actuarial deductions for claiming a pension before the statutory eligibility age. In recent years the employment rate additionally increased due to the abolishment of early retirement pathways for unemployed and women. We find similar correlations between the development of the implicit tax and actual pension claiming behavior (Figure 30).

The evidence in Figures 29 and 30 is highly suggestive. However, these bivariate correlations of a relatively small set of synthetic individuals do not control for the many other potential explanatory factors and the heterogeneity in the population. This requires a much more elaborate multivariate analysis of actual individuals in panel data. The next step of the International Social Security Project will therefore be devoted to a causal analysis of the role of public pension policies in shaping old-age employment. We are doing this by constructing, for each individual and separately for each country, time series of the implicit tax. We will then use these incentive variables, the macro variables considered so far and other determinants on the individual level as explanatory variables in an econometric analysis of retirement and labor force participation. 


\section{References}

Börsch-Supan, A. (1992): Population aging, social security design, and early retirement, Journal of Institutional and Theoretical Economics 148, 533-557.

Börsch-Supan, A. and C. Quinn. 2015. „Taxing pensions and retirement benefits in Germany“, MEADiscussion Paper 10-2015.

Börsch-Supan, A., and H. Jürges. 2012. "Disability, Pension Reform, and Early Retirement in Germany”. In Social Security Programs and Retirement around the World. Historical Trends in Mortality and Health, Employment, and Disability Insurance Participation and Reforms', edited by D. A. Wise, 277-300, The University of Chicago Press, Chicago and London.

Börsch-Supan, A. and I. Ferrari. 2017. “Old-age Labor Force Participation in Germany: What explains the trend reversal among older men? And what the steady increase among women?”, NBER Working Paper No. 24044.

Börsch-Supan, A. and R. Schnabel. 1999, “Social Security and Retirement in Germany”. In Social Security and Retirement around the World, edited by J. Gruber D.A. Wise, 135-180, University of Chicago Press, Chicago and London.

Börsch-Supan, A., T. Bucher-Koenen, S. Kluth, M. Haupt, N. Goll. 2015: „Vor- und Nachteile höherer Flexibilität als Instrument zur Erhöhung der Beschäftigung Älterer“, MEA Discussion Paper 06-2015.

Börsch-Supan, A. and C. Coile (2018). "Social Security Programs and Retirement Around the World: Reforms and Retirement Incentives - Introduction and Summary”, NBER Working Paper 25280, Cambridge, MA.

Commission for Sustainability in Financing the Social Security Systems (Kommission für die Nachhaltigkeit in der Finanzierung der Sozialen Sicherungssysteme). 2003: „Final Report (Abschlußbericht)“. Bundesministerium für Gesundheit und Soziale Sicherheit, Berlin. http://www.bmgs.bund.de/deu/gra/themen/sicherheit/kommission/index.cfm.

Deutsche Rentenversicherung Bund (DRV): 2011, FDZ-Biografiedatensatz für die Biografiedaten der Versicherten (VSKT) 2011.

Deutsche Rentenversicherung Bund (DRV): 2017, Rentenversicherung in Zahlreihen, DRV-Schriften, Band 22, Berlin.

Gasche, M. 2012. „Was sind die richtigen Rentenabschläge? - Neue Perspektiven“, Jahrbuch für Wirtschaftswissenschaften 63(2), 187-235.

Hanel, B. (2010), Financial Incentives to Postpone Retirement and Further Effects on Employment Evidence From a Natural Experiment, Labour Economics, 17(3), 474 - 486

Holthausen, A., J. Rausch and C.B. Wilke. 2012: MEA-PENSIM 2.0: „Weiterentwicklung eines Rentensimulationsmodells, Konzeption und ausgewählte Anwendungen “, MEA-Discussion Paper 3-2012.

OECD, 2018a: "LFS by sex and age - indicators".

http://stats.oecd.org/Index.aspx?DataSetCode=LFS_SEXAGE_I_R.

OECD, 2018b: "Table I.5. Average personal income tax and social security contribution rates on gross labour income”, http://stats.oecd.org/Index.aspx?DataSetCode=TABLE_I5.

Siddiqui, S. (1997): The pension incentive to retire: Empirical evidence for West Germany, Population Economics 10, 463-486. 
Statistisches Bundesamt. 2015. „Generationensterbetafeln für Deutschland, Modellrechnungen für die Geburtsjahrgänge 1896-2009”, Wiesbaden.

Statistisches Bundesamt. 2016. „Mikrozensus, Bevölkerung und Erwerbstätigkeit Stand und Entwicklung der Erwerbstätigkeit in Deutschland”, Wiesbaden.

Werding, M. 2012. „Rentenbemessung und Renteneintrittsalter: Korrekte Abschläge bei vorzeitigem Rentenzugang“, mimeo, Lehrstuhl für Sozialpolitik und öffentliche Finanzen, Ruhr-Universität Bochum. 